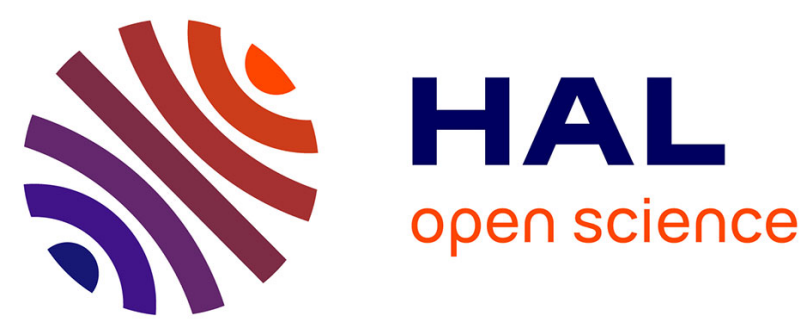

\title{
Comparison of Two Different Cloud Climatologies Derived from CALIOP-Attenuated Backscattered Measurements (Level 1): The CALIPSO-ST and the CALIPSO-GOCCP
}

H. Chepfer, G. Cesana, D. Winker, B. Getzewich, M. Vaughan, Z. Liu

\section{To cite this version:}

H. Chepfer, G. Cesana, D. Winker, B. Getzewich, M. Vaughan, et al.. Comparison of Two Different Cloud Climatologies Derived from CALIOP-Attenuated Backscattered Measurements (Level 1): The CALIPSO-ST and the CALIPSO-GOCCP. Journal of Atmospheric and Oceanic Technology, 2013, 30 (4), pp.725-744. 10.1175/jtech-d-12-00057.1 . hal-01092107

\section{HAL Id: hal-01092107 https://hal.science/hal-01092107}

Submitted on 8 Dec 2014

HAL is a multi-disciplinary open access archive for the deposit and dissemination of scientific research documents, whether they are published or not. The documents may come from teaching and research institutions in France or abroad, or from public or private research centers.
L'archive ouverte pluridisciplinaire HAL, est destinée au dépôt et à la diffusion de documents scientifiques de niveau recherche, publiés ou non, émanant des établissements d'enseignement et de recherche français ou étrangers, des laboratoires publics ou privés. 


\title{
Comparison of Two Different Cloud Climatologies Derived from CALIOP-Attenuated Backscattered Measurements (Level 1): The CALIPSO-ST and the CALIPSO-GOCCP
}

\author{
H. Chepfer, ${ }^{*}$ G. Cesana, ${ }^{+}$D. Winker, ${ }^{*}$ B. Getzewich, ${ }^{@}$ M. VAughan, ${ }^{\#}$ And Z. LiU ${ }^{@}$ \\ * LMD, IPSL, University Pierre and Marie Curie, Paris, France \\ ${ }^{+}$LMD, IPSL, Ecole Polytechnique, Palaiseau, France \\ \# NASA Langley Research Center, Hampton, Virginia \\ @SSAI, Hampton, Virginia
}

(Manuscript received 16 March 2012, in final form 5 October 2012)

\begin{abstract}
Two different cloud climatologies have been derived from the same NASA-Cloud-Aerosol Lidar with Orthogonal Polarization (CALIOP)-measured attenuated backscattered profile (level 1, version 3 dataset). The first climatology, named Cloud-Aerosol Lidar and Infrared Pathfinder Satellite Observations-Science Team (CALIPSO-ST), is based on the standard CALIOP cloud mask (level 2 product, version 3 ), with the aim to document clouds with the highest possible spatiotemporal resolution, taking full advantage of the CALIOP capabilities and sensitivity for a wide range of cloud scientific studies. The second climatology, named GCM-Oriented CALIPSO Cloud Product (CALIPSO-GOCCP), is aimed at a single goal: evaluating GCM prediction of cloudiness. For this specific purpose, it has been designed to be fully consistent with the CALIPSO simulator included in the Cloud Feedback Model Intercomparison Project (CFMIP) Observation Simulator Package (COSP) used within version 2 of the CFMIP (CFMIP-2) experiment and phase 5 of the Coupled Model Intercomparison Project (CMIP5).

The differences between the two datasets in the global cloud cover maps-total, low level $(P>680 \mathrm{hPa})$, midlevel $(680<P<440 \mathrm{hPa})$, and high level $(P<440 \mathrm{hPa})$ - are frequently larger than $10 \%$ and vary with region.

The two climatologies show significant differences in the zonal cloud fraction profile (which differ by a factor of almost 2 in some regions), which are due to the differences in the horizontal and vertical averaging of the measured attenuated backscattered profile CALIOP profile before the cloud detection and to the threshold used to detect clouds (this threshold depends on the resolution and the signal-to-noise ratio).
\end{abstract}

\section{Introduction}

Satellites are the only practical way to document clouds at global scale, but the definition of clouds is not unique in satellite observations. It depends on the data used to build the climatology-the type of instrument (passive, active), the wavelength of the instrument, its sensitivity, the threshold of detection, the spatiotemporal sampling-and also on the scientific question aimed at when developing the cloud algorithm.

An intensive comparison exercise between various cloud climatologies derived from different satellites with passive and active remote sensing instruments is

Corresponding author address: Helene Chepfer, LMD, IPSL, UPMC, Ecole Polytechnique, Palaiseau 91128, France.

E-mail: hélène.chepfer@lmd.polytechnique.fr currently underway within the Global Energy and Water Cycle Experiment (GEWEX) cloud assessment (Stubenrauch et al. 2012). This exercise involves most of the current existing cloud climatologies, from the longest ones [such as the International Satellite Cloud Climatology Project (ISCCP; Rossow and Schiffer 1999) or the Television and Infrared Observation Satellite (TIROS) Operational Vertical Sounder (TOVS; Stubenrauch et al. 1999, 2006)] to the more recent and shorter ones [Moderate Resolution Imaging Spectroradiometer (MODIS), Clouds and the Earth's Radiant Energy System (CERES), Polarization and Directionality of the Earth's Reflectances (POLDER), and CloudAerosol Lidar and Infrared Pathfinder Satellite Observations (CALIPSO)]. The goal of this exercise is not to derive a single answer for each of the cloud variablesthis single answer does not exist—but to synthesize, 
quantify the differences between these cloud climatologies, and explain them based on the instrument sensitivity, or the sampling of the measurement and/or the algorithms used.

Moreover, even for a given raw dataset from one single instrument, the way to proceed from the measured variable to the cloud climatology is not unique. It includes several steps, based on physical choices, that are strongly guided by the scientific question aimed at when building the retrieval algorithm. For this reason, a given measured dataset of a given instrument can lead to different cloud climatologies built to answer different scientific questions. For example, the MODIS Science Team (MODIS-ST; i.e., Platnick et al. 2003) has three different cloud masks: one for studying surfaces, another for studying aerosols, and another one to study clouds. Moreover, the MODIS-Clouds and the Earth's Radiant Energy System (MODIS-CERES) (Minnis et al. 2008) is another dataset specific for studying fluxes. In a similar way, POLDER has different cloud masks: Parol et al. (2004) is dedicated to cloud studies, whereas another cloud mask (Deuzé et al. 2001) is dedicated to aerosol studies. In the current study, we use two different cloud datasets [CALIPSO Science Team (CALIPSO-ST) and GCM-Oriented CALIPSO Cloud Product (CALIPSOGOCCP)] derived from the same CALIPSO attenuated backscatter signal (level 1 raw data).

Since 2006, two active remote sensors-the lidar Cloud-Aerosol Lidar with Orthogonal Polarization (CALIOP) (Winker et al. 2007; Winker et al. 2010) and the radar CloudSat (Stephens et al. 2002) - have been flying on board satellite platforms and give complementary information on the spatiotemporal distribution of clouds. In particular, these two instruments collect raw signals at an unprecedented vertical resolution of 30 (CALIPSO) and $480 \mathrm{~m}$ (CloudSat) that can be used to derive the cloud vertical distribution with a precision that was not possible before from space.

In the current paper, we make a detailed comparison between two different cloud climatologies derived from the CALIOP-measured attenuated backscatter profile: (i) the CALIPSO-ST climatology derived from the CALIOP cloud mask [level 2 National Aeronautics and Space Administration (NASA)] dataset, which was built with the aim of taking the greatest possible advantage of the high sensitivity and high vertical resolution of the CALIOP sensor; and (ii) the CALIPSO-GOCCP climatology, which was built for a single goal: the evaluation of the representation of clouds in climate models.

Even though both cloud climatologies are derived from the same CALIOP-measured attenuated backscattered profiles, identical results are not expected because the physical choices made in each algorithm are guided by different scientific objectives. The aim of this paper is to highlight and explain these differences in order to avoid misinterpretation by users. The comparison between the two datasets presented is based on 1 year of observations (September 2006 to August 2007).

As the algorithms used have been presented in previous papers, only a short summary of the content of each algorithm is given in section 2 , with specific emphasis being given to their main differences and to recent algorithm improvements since last publication.

The results obtained from the two different cloud masks are examined for selected orbits dedicated to specific cloud types in section 3: tropical oceanic shallow cumulus, optically thin high-altitude cirrus, polar clouds, midlevel clouds in the storm tracks, deep convective clouds, etc. Global seasonal statistics obtained from the two algorithms are compared quantitatively in section 4 : total cloud cover, low $(P>680 \mathrm{hPa})$, middle $(680>P>$ $440 \mathrm{hPa})$, and high $(P<440 \mathrm{hPa})$ cloud cover. Section 5 is devoted to the comparison of the zonal cloud fraction profile, which is novel and unique global-scale information provided by CALIOP. The two new climatologies discussed here-GOCCP and ST-provide the vertically resolved cloud fraction over the entire troposphere with a vertical resolution of $480 \mathrm{~m}$.

Each section discusses the results of the comparison in terms of cloud detection thresholds, horizontal and vertical averaging, and lidar sensitivity.

\section{Presentation of the algorithms: Short description, key steps, and differences}

CALIOP is a nadir-pointing instrument and acquires lidar profiles at 532 and $1064 \mathrm{~nm}$ along the CALIPSO ground track. The laser footprints have a diameter of about $70 \mathrm{~m}$ with a center-to-center spacing of $1 / 3 \mathrm{~km}$. The data are averaged vertically and horizontally on board the satellite so that downlinked data have a resolution of $1 / 3 \mathrm{~km}$ horizontally and $30 \mathrm{~m}$ below $8-\mathrm{km}$ altitude, and $1 \mathrm{~km}$ and $60 \mathrm{~m}$ from 8 to $20 \mathrm{~km}$ (Hunt et al. 2009). The two cloud climatologies-CALIPSO-ST and CALIPSO-GOCCP - are built from the same CALIOP measurements composed of 532-nm attenuated backscatter lidar profiles (ATB), and a horizontal sampling of $1 / 3-\mathrm{km}$ along track and $70-\mathrm{m}$ cross track, although they use independent algorithms to detect clouds and to construct a gridded climatology.

\section{a. CALIPSO-GOCCP}

The definition of clouds or cloud types is not unique. It differs among observations (e.g., clouds detected by a lidar may not be detected by a radar or by passive remote sensing), and among climate models (e.g., 
conversion from condensed water to cloud cover is not direct), and between models and observations (e.g., models predict clouds at each atmospheric level where condensation occurs, while observations may not detect clouds overlapped by thick upper-level clouds). A comparison between modeled and observed clouds thus requires a consistent definition of clouds, taking into account the effects of viewing geometry, sensors' sensitivity, and vertical overlap of cloud layers. For this purpose, clouds simulated by climate models are often compared to observations through a model-to-satellite approach: model outputs are used to diagnose some quantities that would be observed from space if satellites were flying above an atmosphere similar to that predicted by the model (e.g., Yu et al. 1996; Klein and Jakob 1999; Webb et al. 2001; Zhang et al. 2005; Bodas-Salcedo et al. 2008; Chepfer et al. 2008; Marchand et al. 2009).

Within the framework of the Cloud Feedback Model Intercomparison Project (CFMIP; http://www.cfmip. net), the Observation Simulator Package (OSP; Bodas et al. 2011) has been developed to compare in a consistent way the cloud cover predicted by climate models with that derived from different satellite observations. The purpose of CALIPSO-GOCCP is to diagnose cloud properties from $C A L I P S O$ observations in exactly the same way as in the simulator (similar spatial resolution, same criteria used for cloud detection, same statistical cloud diagnostics). This ensures that discrepancies between model and observations reveal biases in the model's cloudiness rather than differences in the definition of clouds or of diagnostics.

Nevertheless, even a "perfect" match between COSP results for a given GCM and the corresponding GOCCP product will not absolutely guarantee that the GCM is perfectly reproducing all clouds, because GOCCP, like every observational dataset, does not pretend to observe perfectly all clouds.

COSP/lidar (Chepfer et al. 2008) simulates the lidarattenuated backscattered signal in each subgrid box at a vertical resolution of $480 \mathrm{~m}$ (40 levels) starting from the ground. Clouds are detected by constructing profiles of attenuated scattering ratio $\operatorname{SR}(z)$ defined as

$$
\operatorname{SR}(z)=\operatorname{ATB}(z) / \operatorname{ATB}_{\text {mol }}(z),
$$

where $\operatorname{ATB}(z)$ is the calibrated 532-nm lidar return signal and $\mathrm{ATB}_{\text {mol }}(z)$ is the 532-nm molecular return signal that would be measured in a cloud-free and aerosol-free atmosphere. Clouds are detected from the SR profiles on a fixed vertical grid (480 m), using a single constant threshold: $\mathrm{SR}>5$ is declared cloudy. The cloud cover is derived statistically by accumulating profiles at a grid scale of $2^{\circ} \times 2^{\circ}$.
Consistent with the lidar simulator, construction of the CALIPSO-GOCCP dataset (fully described in Chepfer et al. 2010) aims at being simple, robust, easy to understand by modelers, consistent in day and night, and avoiding as much as possible false cloud detection, which implies not detecting the optically thinner clouds. For being sure to observe the smallest-sized clouds, such as the shallow cumulus boundary layer clouds, GOCCP uses the highest horizontal resolution possible $(1 / 3 \mathrm{~km})$.

CALIPSO-GOCCP algorithm consists of the following steps: (i) compute the ATBmol by normalization to a noncloudy area within the stratosphere; (ii) average the CALIPSO level 1 ATB to 40 vertical levels equidistant of $480 \mathrm{~m}$, retaining the full horizontal alongtrack resolution $(1 / 3 \mathrm{~km})$; (iii) compute the SR profile; (iv) for each profile detect the presence of clouds at each 480-m level (the pixel is declared cloudy when SR $>5$ and ATB-ATB mol $>2.5 \times 10^{-3} \mathrm{~km}^{-1} \mathrm{sr}^{-1}$ ); and (v) accumulate the cloudy and clear pixels within each grid box (typically $2^{\circ}$ latitude $\times 2^{\circ}$ longitude).

Daytime profiles that are considered too noisy based on the normalization ratio in the stratosphere are rejected ( $30 \%$ of daytime profiles). This may result in an underestimate of cloudy pixels in daytime, as the solar photons reflected from bright clouds increase the noise in the lidar signal.

Two main changes in the CALIPSO-GOCCP algorithm have been done since Chepfer et al. (2010):

1) Improvement of the Surface Detection

Close to the surface, the attenuated backscatter signal at $30-\mathrm{m}$ vertical resolution can increase significantly (ATBstrong $>1 \mathrm{~km}^{-1} \mathrm{sr}^{-1}$ in clear-sky profile and $0.4 \mathrm{~km}^{-1} \mathrm{sr}^{-1}$ otherwise) because of the reflection on the surface produced by snow or by a change in ground altitude. This increased ATB at 30-m vertical resolution can contaminate the value of ATB at $480-\mathrm{m}$ vertical resolution.

To avoid an artificial increase of ATB (at 480-m vertical resolution) due to this surface echo, all the pixels (at 30-m vertical resolution) located below the strong backscatter signal (ATBstrong) and $90 \mathrm{~m}$ above it are rejected.

2) Daytime Improvement

During daytime, solar photons are reflected by optically thick low-level clouds (typically stratocumulus, SR > 30), which decreases the signal-to-noise ratio (SNR) at altitudes located above the boundary layer clouds, producing false cloud detections below $8 \mathrm{~km}$, where the CALIOP-measured attenuated backscattered profile is $1 / 3-\mathrm{km}$ horizontal resolution (this is less the case above $8 \mathrm{~km}$, where the SNR remains roughly 1.5 times higher because of averaging to $1-\mathrm{km}$ horizontal resolution). As the vertical resolution ( $480 \mathrm{~m}$ for consistency with the 
simulator) as well as the horizontal resolution $(1 / 3 \mathrm{~km}$ below $8 \mathrm{~km}$ and $1 \mathrm{~km}$ above, but sampled on $1 / 3 \mathrm{~km}$ ) are constant in CALIPSO-GOCCP, we ensure the consistency of cloud detection by multiplying the cloud detection threshold by $3(\mathrm{SR}=3 \times 5=15)$ between 2.4 and $8.16 \mathrm{~km}$ in daytime in the presence of low-level clouds (SR $>30$ below $z<3.36 \mathrm{~km}$ ), which avoids false detection of mid- and high-level cloud between 3.36- and 8.16-km altitude.

\section{b. CALIPSO-ST}

A complex threshold-based detection algorithm is used to produce CALIOP cloud and aerosol mask (Winker et al. 2009). Clouds are detected in single-shot profiles and also in horizontally averaged profiles, in order to allow for the detection of optically thin clouds. Detection thresholds are adjusted according to profile SNR and the detection scheme compensates for the attenuation of overlying layers (Vaughan et al. 2009). CALIPSO-ST is built from CALIOP version 3 data and is constructed by combining several of the CALIOP layer products into intermediate level 2 data files. Screening is applied to the intermediate files and the resulting data are then binned onto the same grid as used by $C A L I P S O$-GOCCP: a three-dimensional grid of $2^{\circ} \times$ $2^{\circ} \times 480 \mathrm{~m}$ vertically.

\section{1) COnstruction OF CALIOP LeVEL 2 PRODUCTS}

Dense clouds can be detected in single-shot profiles, but detection of optically thin clouds requires averaging of multiple lidar shots. To preserve the structure of broken cloud fields yet also allow the detection of optically thin clouds, a multiscale averaging scheme is used to detect both weakly and strongly scattering clouds with the minimum necessary amount of horizontal averaging (Vaughan et al. 2009; Winker et al. 2009). Cloud and aerosol layers are detected using a threshold technique applied to profiles of attenuated scattering ratio $\operatorname{SR}(z)$. After layers are detected, an algorithm is applied to discriminate between cloud and aerosol (Liu et al. 2009), except for layers detected in single-shot $(1 / 3 \mathrm{~km})$ profiles, which are assumed to be cloud.

As the SNR decreases, detection thresholds are increased to avoid false detections due to noise. The detection threshold varies with altitude, with solar background levels and horizontal averaging interval. Detection is performed on 532-nm data, except for single-shot profiles (available from -0.5 - to $8.2-\mathrm{km}$ altitude), where $1064 \mathrm{~nm}$ data are used (Vaughan et al. 2009). Figure 1 shows the threshold values used in detecting cloud and aerosol layers. Higher thresholds are used during daytime than at night because SNR is

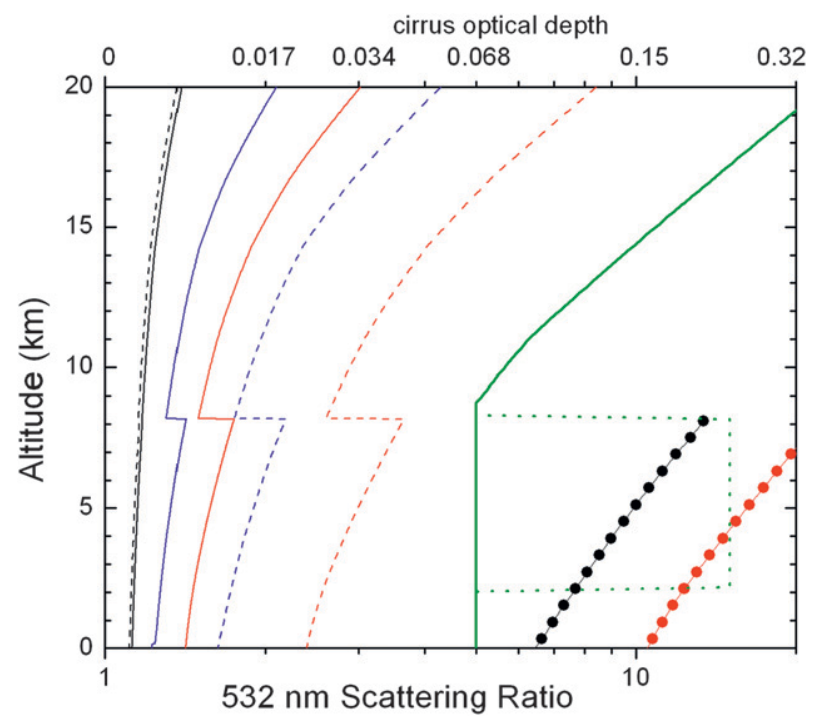

FIG. 1. Detection thresholds used in the CALIPSO-ST and $C A L I P S O-G O C C P$ detection algorithms. Solid green line is the standard threshold used for-GOCCP. Green dotted line indicates threshold used for-GOCCP during daytime over bright, low-level clouds. Black curves are nighttime thresholds used by -ST. Blue and red curves are daytime thresholds used for low and high solar background conditions, respectively. Dashed and solid lines indicate thresholds used for detection of layers with 5 - and $80-\mathrm{km}$ horizontal averaging, respectively. (bottom right) Black (night) and red (day, high background) curves with filled circles represent equivalent 532-nm scattering ratio thresholds for detection of cloud tops below $8 \mathrm{~km}$ in 1064-nm single-shot profiles. The top axis is labeled with the detection threshold in equivalent cirrus optical depth. These values assume a 1-km-thick cirrus cloud at an altitude of $8 \mathrm{~km}$ with the ratio of cirrus extinction to $180^{\circ}$ backscatter $S=25 \mathrm{sr}$. The optical depth threshold varies less than a factor of 2 for cirrus located at other altitudes.

reduced by solar background illumination, so weakly scattering clouds that are detected at night may be missed during daytime. Above an altitude of $8.2 \mathrm{~km}$, two $30-\mathrm{m}$ vertical bins are averaged (on board the satellite) to $60 \mathrm{~m}$. This improves the SNR and thresholds are decreased accordingly. The lidar signal is partially attenuated by each cloud layer it passes through. The ST algorithm estimates and corrects the signal below the cloud for this attenuation (Vaughan et al. 2009). Without this attenuation correction, the detection algorithm would become progressively less sensitive after passing through increasing amounts of attenuating cloud.

Detection is initially performed on profiles averaged over 15 consecutive shots, corresponding to a horizontal resolution of $5 \mathrm{~km}$. When layers are detected in these averaged profiles, the highest-resolution profiles $(1 / 3 \mathrm{~km}$ below $8-\mathrm{km}$ altitude and $1 \mathrm{~km}$ above) are rescanned to detect clouds at the highest possible resolution. If clouds with tops below $4 \mathrm{~km}$ are found in the $1 / 3-\mathrm{km}$ profiles, these data are removed and the 15 shots are reaveraged 
and rescanned to detect weaker layers. Following this, additional scans are conducted after averaging over 60 shots $(20 \mathrm{~km})$ and 240 shots $(80 \mathrm{~km})$. At each step, clouds detected at finer horizontal resolutions are removed from the scattering ratio profiles before further averaging, to avoid them being averaged together with as yet undetected, more weakly scattering clouds. In this way, cloud detection is performed after the least amount of averaging required and the overestimation of cloud cover because averaging over broken clouds is avoided as much as possible. Clouds detected in single-shot profiles are reported in the $1 / 3-\mathrm{km}$ cloud layer product, while cloud layers detected at 5, 20, and $80 \mathrm{~km}$ are all reported in the $5-\mathrm{km}$ cloud layer product.

A number of studies have evaluated CALIOP cloud detection and CALIOP level 2 cloud products. McGill et al. (2007), using the cloud physics lidar (CPL) carried on the NASA ER-2, determined a daytime detection limit of SR $=5$ for cirrus at an altitude of $15 \mathrm{~km}$ for CALIOP data averaged horizontally to $5 \mathrm{~km}$, consistent with the threshold shown in Fig. 1. Davis et al. (2010), comparing CALIOP with CPL in a study of tropical subvisible cirrus, found a daytime optical depth detection limit of 0.005-0.01. Yorks et al. (2011), again comparing CALIOP and CPL observations of midlatitude cirrus, found good agreement in both cloud fraction and the vertical profile of cloud occurrence. Thorsen et al. (2011) compared 31 months of tropical cirrus observations from CALIOP with micropulse lidar observations from three sites in the tropical western Pacific. Good consistency between the satellite- and ground-based observations was found for both cloud fraction and the vertical profile of cloud occurrence. Medeiros et al. (2010) investigated lowlatitude boundary layer clouds using the CALIOP $1 / 3$ - and $1-\mathrm{km}$ cloud layer products, finding that the CALIOP cloud products reveal the expected patterns of marine stratus and trade wind cumulus.

\section{2) Merging}

CALIPSO-ST is produced by merging several of the CALIOP level 2 data products. Intermediate files are produced on a grid of $1 / 3 \mathrm{~km} \times 60 \mathrm{~m}$, from the surface to $20-\mathrm{km}$ altitude. Clouds reported in the $1 / 3-\mathrm{km}$ cloud layer product, which only contains clouds with tops between the surface and $8 \mathrm{~km}$, are first registered onto the grid. Clouds detected at 5, 20, and $80 \mathrm{~km}$ are all reported in the 5-km cloud layer product, on a 5-km horizontal grid. The cloud fraction reported in the $5-\mathrm{km}$ cloud layer product is either 0 or 1 for each $5-\mathrm{km}$ column. Cloudy columns may contain one cloud layer or several. For each layer in the $5-\mathrm{km}$ cloud layer product, each of the 15 corresponding $1 / 3-\mathrm{km}$ profiles in the intermediate file is marked as "cloudy" between the base and top altitudes of the detected layer. CALIPSO-ST is constructed using all ice clouds reported in the 5 - and $1 / 3-\mathrm{km}$ layer products. Water clouds are only taken from the $1 / 3-\mathrm{km}$ layer product, as detection sensitivity at $1 / 3 \mathrm{~km}$ is sufficient to detect water clouds with optical depths as small as 0.1.

It has been noticed that optically thin ice clouds in the polar regions, particularly during polar night, are sometimes classified as aerosols. Aerosol loading above the Antarctic Plateau is so low that the aerosol is almost always below the CALIOP detection limit. Therefore, any aerosol layers reported in the aerosol layer product over the Antarctic Plateau (poleward of $60^{\circ} \mathrm{S}$ and surface height greater than $2 \mathrm{~km})$ or Greenland $\left(60^{\circ}-90^{\circ} \mathrm{N}\right.$, $25^{\circ}-60^{\circ} \mathrm{W}$ and surface above $2 \mathrm{~km}$ ) and with a layer top of $8 \mathrm{~km}$ or less are assumed to be misclassified and are included in CALIPSO-ST as cloud layers.

\section{3) SCREENING}

Several tests are applied to determine if a given $5-\mathrm{km}$ cloud layer should be included. The cloud-aerosol discrimination (CAD) score indicates the confidence of the CAD algorithm in classifying a layer as either aerosol or cloud. The CALIPSO-ST product is meant to characterize tropospheric clouds, so polar stratospheric clouds (PSCs) are screened out by ignoring any cloud layer poleward of $60^{\circ}$ that has a base altitude greater than or equal to $9 \mathrm{~km}$. This test only has an effect during PSC season, which is roughly June-October in Antarctica (Pitts et al. 2007; Noel et al. 2008, 2009) and a shorter period during Arctic winter.

\section{4) BINNING}

After screening of the intermediate files, the final step is to bin the data to the three-dimensional grid used by GOCCP. In each $1 / 3-\mathrm{km}$ column of the intermediate files, if any of the $60-\mathrm{m}$ vertical bins is cloudy, the corresponding 480-m vertical bin is marked as cloudy. At each $480-\mathrm{m}$ vertical level, the fraction of cloudy $1 / 3-\mathrm{km}$ columns within each $2^{\circ} \times 2^{\circ}$ grid cell is then computed to determine the cloud fraction at that level.

\section{c. Primary differences between CALIPSO-ST and CALIPSO-GOCCP}

Previous subsections $2 \mathrm{a}$ and $2 \mathrm{~b}$ indicate that the main differences between the two algorithms are the thresholds used for cloud detection, the CAD algorithm to determine whether the detected layers are aerosols or cloud (ST only), and the adjustment of the thresholds in producing the standard CALIOP-ST level 2 product to account for cloud attenuation, which is applied to each independent CALIOP-attenuated backscattered profile.

Basically, CALIPSO-GOCCP increases the signal-tonoise ratio by averaging level 1 data vertically (over $480 \mathrm{~m}$ ) 
(a) CALIPSO-GOCCP Mask Low $=0.405$
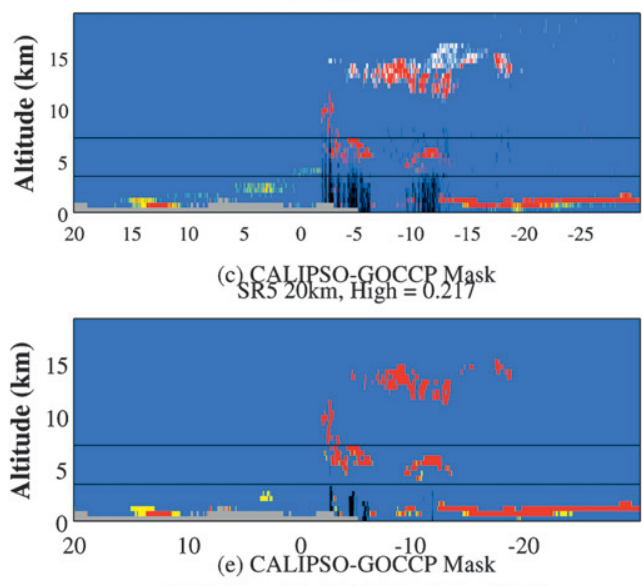

SR2 20km delta $($ ATB $)=0$, High $=0.385$

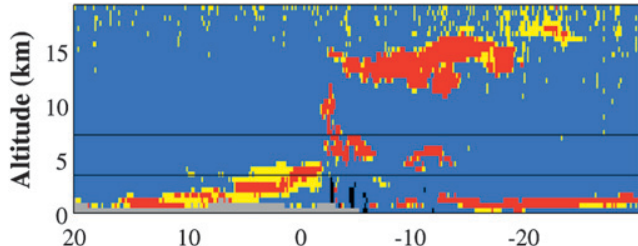

(g) CALIPSO-ST Vertical Feature Mask

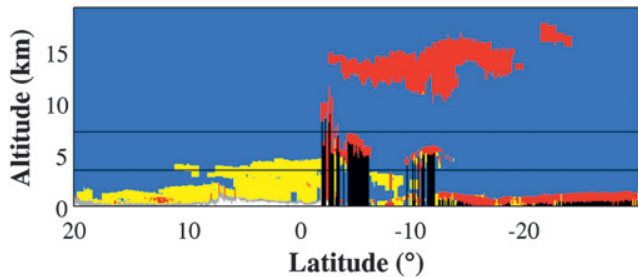

(b) CALIPSO-ST Cloud Fraction Low $=0.398$

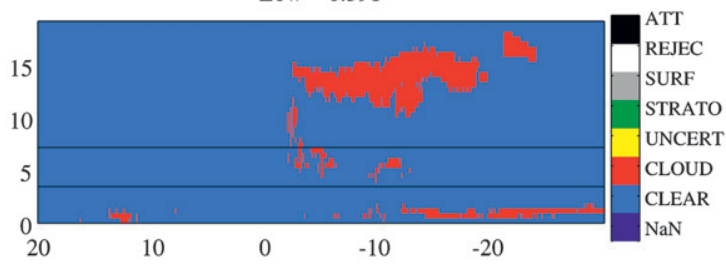

(d) GOCCP Mask SR5 20km delta(ATB) $=0$ High $=0.282$

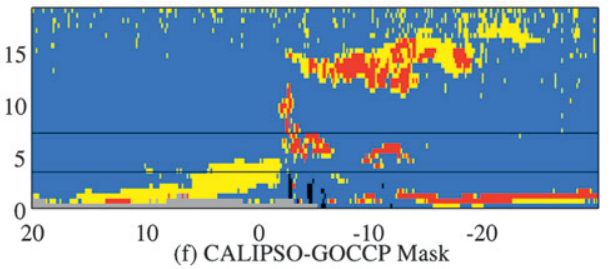

SR2 80km delta(ATB) $=0$, High $=0.387$

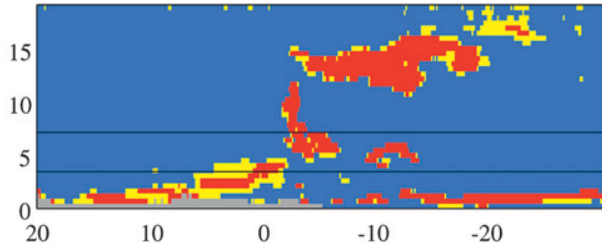

(h) CALIPSO-GOCCP Scattering Ratio

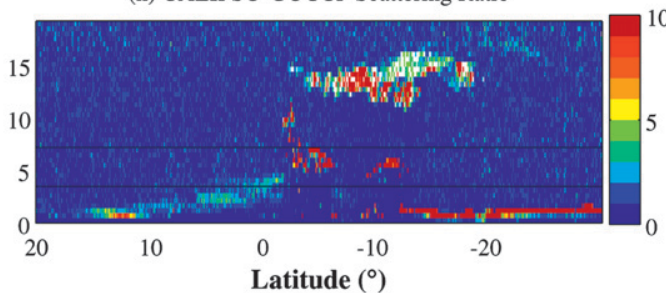

FIG. 2. Nighttime orbit segment crossing the equator at about $13^{\circ} \mathrm{E}$ showing observations over the Sahara and the southeast Atlantic Ocean on 1 Jan 2001 (2007-01-01T00-22-49ZN). Cloud masks: (a) CALIPSO-GOCCP; CF-low = $40.5 \%$, CF-high $=21.4 \%$. (b) CALIPSO-ST; CF-low $=39.7 \%$, CF-high $=40.7 \%$. (c) CALIPSO-GOCCP $20-\mathrm{km}$ horizontal averaging. (d) CALIPSO-GOCCP 20-km horizontal averaging, cloud detection threshold $\mathrm{SR}=5, \triangle \mathrm{ATB}=$ 0. (e) CALIPSO-GOCCP 20-km horizontal averaging, cloud detection threshold $\mathrm{SR}=2, \triangle \mathrm{ATB}=0$. (f) $C A L I P S O$ GOCCP 80-km horizontal averaging, cloud detection threshold $\mathrm{SR}=5, \triangle \mathrm{ATB}=0$. (g) CALIPSO-ST vertical feature mask version 2. (h) CALIPSO-GOCCP scattering ratio: white color corresponds to SR $>5$ and $\triangle \mathrm{ATB}<2.5 \times$ $10^{-3} \mathrm{~km}^{-1} \mathrm{sr}^{-1}$.

and keeping the full horizontal resolution $(1 / 3 \mathrm{~km})$, whereas CALIPSO-ST increases the signal-to-noise ratio by averaging horizontally over various distances and keeping the full vertical resolution (30 and $60 \mathrm{~m}$ ).

CALIPSO-GOCCP produces a cloud mask at a single resolution of $1 / 3 \mathrm{~km}$. This single cloud mask is built using a fixed detection threshold (SR $>5$ and ATB-ATB mol $>$ $2.5 \times 10^{-3} \mathrm{~km}^{-1} \mathrm{sr}^{-1}$ ) applied to a given vertical $(480 \mathrm{~m})$ and horizontal grid $(330 \mathrm{~m}$ along track and $75 \mathrm{~m}$ cross track), except above stratocumulus in daytime (see previous section) and there is no correction for attenuation. Any layer exceeding the GOCCP threshold is assumed to be a cloud.

CALIPSO-ST produces a cloud mask based on the detection of atmospheric layers at several different horizontal resolutions and different values of the detection threshold. Detected layers are classified as either aerosol or cloud. The horizontal extent of detected cloud layers ranges from $1 / 3$ to $80 \mathrm{~km}$. The averaging of attenuated backscattered profiles allows for detection of optically very thin clouds. The detection threshold varies with altitude and lighting conditions, as well as depending on the degree of averaging employed.

Figure 1 contrasts the range of cloud detection thresholds and horizontal averaging used in CALIPSO-ST with the fixed cloud detection threshold used in CALIPSOGOCCP. The ST threshold is set depending on lighting conditions, the "low" and "high" numbers represent thresholds used over dark and bright surfaces, respectively, 


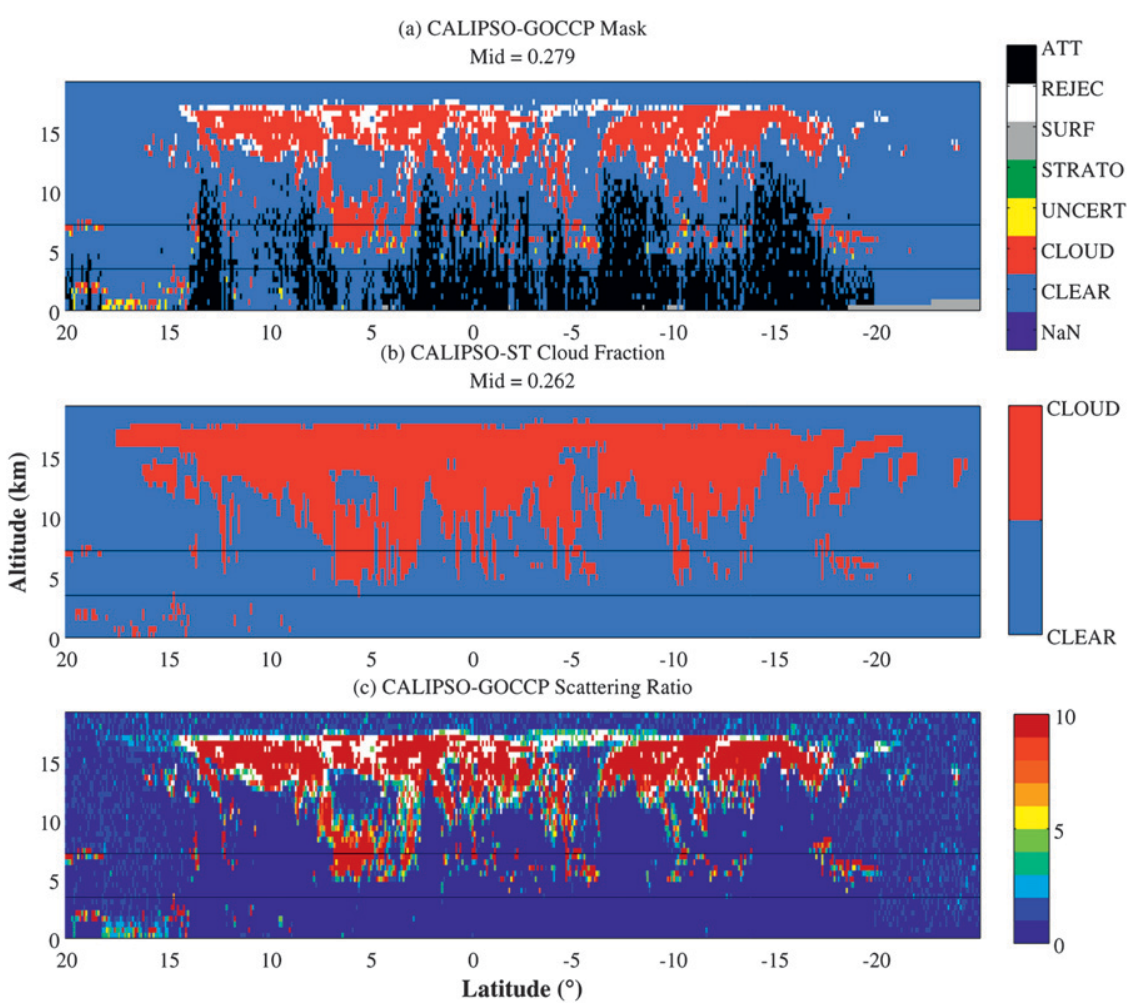

FIG. 3. Nighttime orbit segment illustrating the detection of cloud at midlevels in the tropical western Pacific Ocean. (2007-01-01T16-51-41ZN). (a) CALIPSO-GOCCP cloud mask. (b) CALIPSO-ST cloud mask scattering ratio (white areas correspond to SR $>5$ and $\triangle \mathrm{ATB}<2.5 \times 10^{-3} \mathrm{~km}^{-1} \mathrm{sr}^{-1}$ ). (c) Scattering ratio (white areas correspond to SR $>5$ and $\Delta$ ATB $<2.5 \times 10^{-3} \mathrm{~km}^{-1} \mathrm{sr}^{-1}$ ).

and are meant to represent low and high daytime limits. The threshold scattering ratio values shown in Fig. 1 can be related to cirrus optical depth. The threshold used by GOCCP at night corresponds to a cirrus with 1-km thickness, and optical depth of about $0.07 \mathrm{up}$ to an altitude of $8 \mathrm{~km}$ and increases above that. The thresholds used by ST on single-shot profiles allow for detection of cirrus optical depths of 0.3 , even during daytime. Averaging allows for detection of more tenuous cirrus with optical depths as low as about 0.02 during day and 0.005 at night.

In the next section, we compare the cloud detection along individual orbit tracks for several typical cloud scenes in order to highlight the behaviors of the two algorithms.

\section{Cloud detection}

\section{a. High clouds}

Figure 2 shows that the high cloud amounts detected by ST (Fig. 2b) along this given orbit are larger than the amount detected by GOCCP (Fig. 2a).
As seen from the scattering ratios shown in Fig. 2h, GOCCP will miss most of the subvisible cirrus because of the cloud detection threshold used at altitudes higher than $8 \mathrm{~km}$ (shown in Fig. 1), and applied to profiles with a vertical resolution of $480 \mathrm{~m}$ and a full horizontal resolution of $1 \mathrm{~km}$. Consequently, GOCCP will not detect high clouds with an optical depth smaller than about 0.07 (refer to previous section; see also Chepfer et al. 2010). This can be seen in Fig. 2h (in white), where much of the high cloud has scattering ratio less than 5 .

On the other hand, for high cloud scenes, ST will typically use a detection threshold SR $<1.5$ during nighttime (Fig. 1), at the full vertical resolution of $60 \mathrm{~m}$ above $8 \mathrm{~km}$ of altitude. With a minimum horizontal averaging of $5 \mathrm{~km}$ above $8 \mathrm{~km}$, there is a potential to overestimate the cloud fraction because of clouds with horizontal extent less than $5 \mathrm{~km}$. Clouds are detected with the minimum required amount of averaging. Clouds detected with 20 (80)-km averaging were not with 5 (20)-km averaging.

Lidar In-Space Technology Experiment (LITE) observations, with a higher sensitivity than CALIOP, show the horizontal extent of thin cirrus cloud is in most cases 


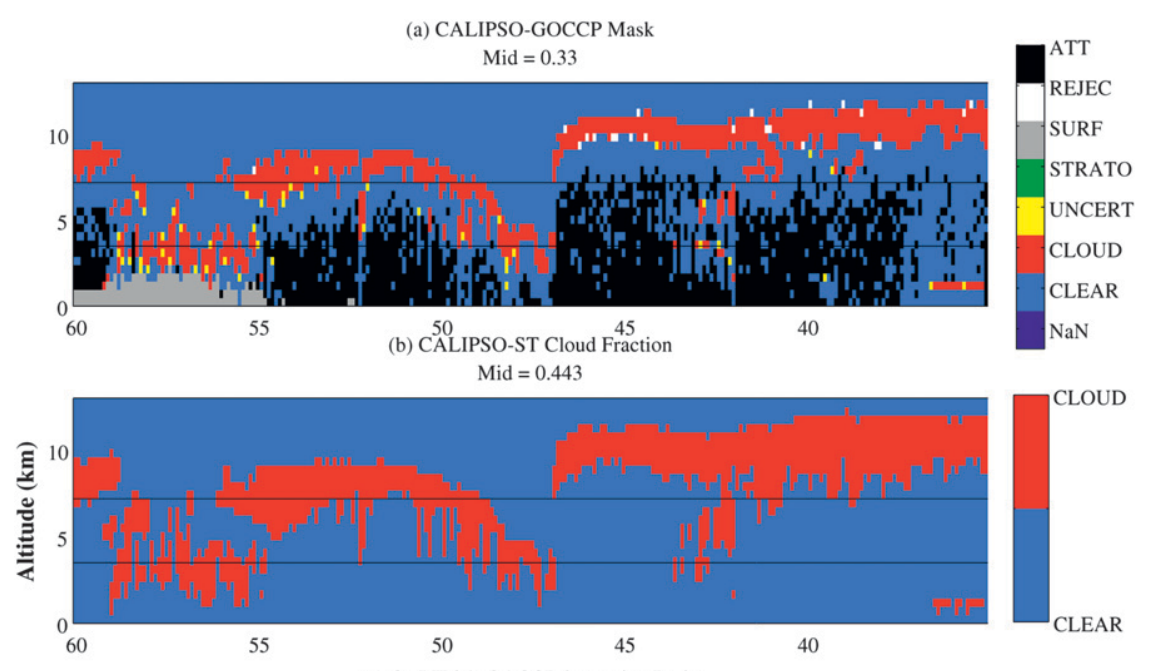

(c) CALIPSO-GOCCP Scattering Ratio

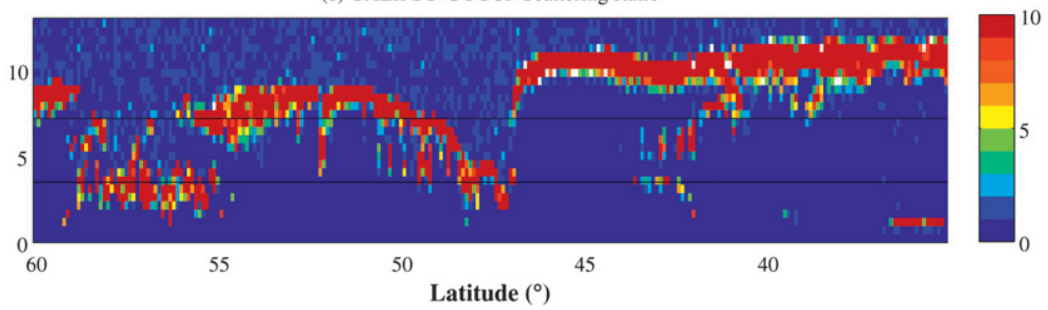

FIG. 4. Nighttime orbit segment illustrating the detection of midlevel midlatitude clouds over the northeastern Pacific Ocean. (2007-01-02T10-59-24ZN). (a) CALIPSO-GOCCP cloud mask. (b) CALIPSO-ST cloud mask. (c) Scattering ratio (white areas correspond to SR $>5$ and $\triangle \mathrm{ATB}<2.5 \times 10^{-3} \mathrm{~km}^{-1} \mathrm{sr}^{-1}$ ).

larger than $50 \mathrm{~km}$, suggesting that broken clouds may thus not play any significant role (Winker et al. 1998). The LITE dataset also shows that the vertical extent of the thinnest tropical tropopause-layer clouds is about $250 \mathrm{~m}$, suggesting that the vertical resolutions used in ST $(60 \mathrm{~m})$ and GOCCP $(480 \mathrm{~m})$ should both detect correctly the presence of these clouds.

To evaluate the impact of the cloud detection threshold and horizontal averaging on cloud cover, we computed the cloud fraction (CF) for various amounts of horizontal averaging [1, 20, 40 (not shown), and $80 \mathrm{~km}]$ and for various detection thresholds ( $\mathrm{SR}=5, \mathrm{SR}=2$, ATB$\mathrm{ATB}_{\mathrm{mol}}=0$ ). The cloud detection threshold (Figs. 2c-e) strongly impacts the detection of high clouds at $20-\mathrm{km}$ horizontal resolution: CF-high increases from 0.36 to 0.64. But such a low detection threshold cannot be applied at very high horizontal resolution (1 instead of $20 \mathrm{~km}$ ) because of the lower signal-to-noise ratio.

The cloud cover obtained for this orbit is almost insensitive to the horizontal resolution as long as it is larger than $20 \mathrm{~km}$ : the results obtained at $80-\mathrm{km}$ horizontal resolution are similar to the $20-\mathrm{km}$ results.

Figure $2 \mathrm{c}$ shows that averaging to $20 \mathrm{~km}$ (with the standard GOCCP threshold) does not increase the cloud fraction of high cloud. Figures $2 \mathrm{~d}$ and $2 \mathrm{e}$ show that reducing the threshold increases cloud fraction but also increases false positive detections. Figure $2 \mathrm{f}$ shows additional averaging to $80 \mathrm{~km}$ does not substantially increase cloud fraction but reduces false positives and gives a result similar to ST.

\section{b. Midlevel clouds}

In tropical deep convective conditions during nighttime (Fig. 3), GOCCP and ST detect a similar amount of clouds in the midtroposphere (CF-mid $=28 \%$ for GOCCP and $26 \%$ for ST), even when the clouds are located beneath a high-level cloud (because the midlevel clouds are strongly scattering and are detected even without attenuation correction). Larger differences (not shown) occur in the tropics during daytime because a significant number of profiles are rejected in GOCCP because of the lower signal-to-noise ratio, and we do not know if the profiles rejected are clear or cloudy.

In the midlatitudes during nighttime, the midlevel cloud amount detected by ST (44\%) is larger than the one detected by GOCCP (33\%) (Figs. 4a and 4b) when they are located beneath a high cloud. There are two 


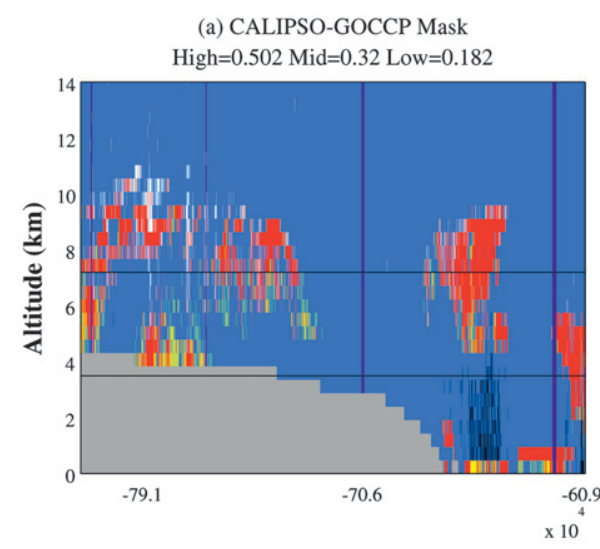

(c) CALIPSO-ST Vertical Feature Mask

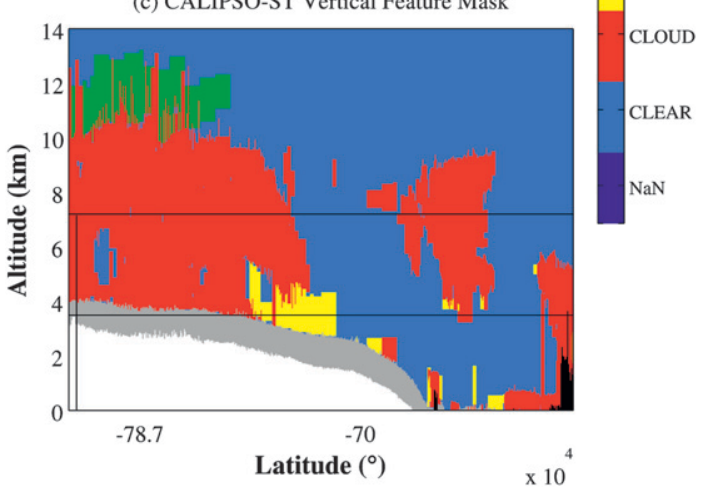

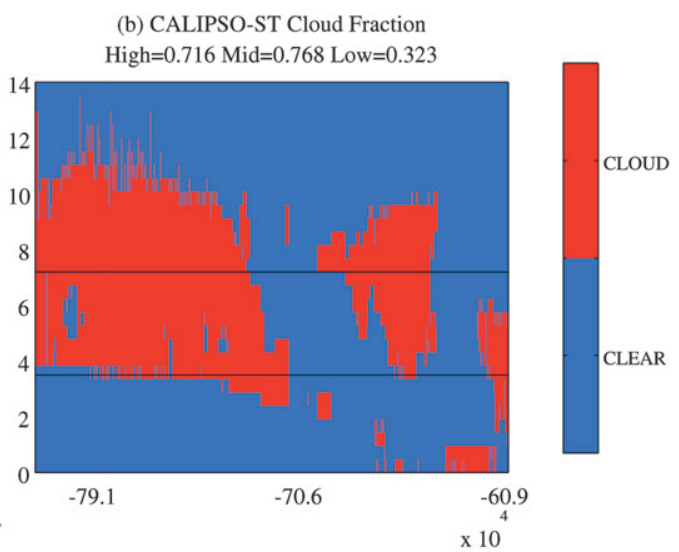

(d) CALIPSO-GOCCP Scattering Ratio

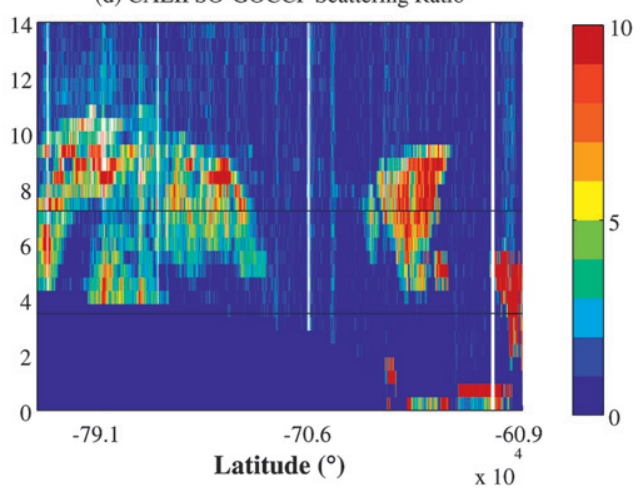

FIG. 5. Nighttime orbit segment over Antarctica, nighttime (2006-09-12T16_04-22ZN). (a) CALIPSO-GOCCP cloud mask. (b) CALIPSO-ST cloud detection. (c) CALIPSO-ST cloud mask. (d) Scattering ratio.

reasons for this, but they are not independent: (i) ST uses a lower detection threshold and (ii) ST accounts for attenuation of overlying cloud when locating cloud bases (GOCCP uses a fixed threshold).

In the midlatitudes during daytime (not shown), the differences between GOCCP and ST are comparable to the ones for nighttime (Figs. $4 a$ and $4 b$ ).

\section{c. Boundary layer clouds}

For boundary layer cloud with no high cloud above (the lidar return signal is not attenuated before hitting the boundary layer cloud), seen in Fig. 2 between $25^{\circ}$ and $30^{\circ} \mathrm{S}$, GOCCP (Fig. 2a) and ST (Fig. 2b) use the same horizontal resolution $(1 / 3 \mathrm{~km})$ but different detection thresholds. They both detect the same clouds because the liquid clouds under study scatter strongly enough to exceed the detection thresholds of both algorithms.

The values of total, low, mid-, and high cloud fractions along the orbit segment shown in Fig. 2 are computed similarly in GOCCP and ST: these low, mid-, and high cloud fractions are defined as the number of profiles containing a cloud in a given altitude range (low, mid-, or high) divided by the total number of profiles along the piece of orbit. As expected from looking at Fig. 2, the low-level cloud cover in ST (39.8\%) and GOCCP $(40.5 \%)$ is very similar. Note that the low cloud cover is significantly different between ST version 3 and ST version 2. GOCCP is in much better agreement with the ST version 3 used in this study than it was with ST version 2 (not shown).

\section{d. Discrimination between dust and low-level clouds}

Figure $2 \mathrm{~g}$ shows a significant presence of dust (yellow) between $0^{\circ}$ and $20^{\circ} \mathrm{N}$. GOCCP (Fig. 2a) and ST (Fig. 2b) report about the same amount of low cloud in this region $(\mathrm{CF}-\mathrm{low}-\mathrm{GOCCP}=0.11$ and CF-low-ST $=0.13)$. The low-altitude "cloud" reported by both GOCCP and ST between $10^{\circ}$ and $15^{\circ} \mathrm{N}$ is strongly scattering dust, likely produced by a dust storm. Dense dust that produces lidar backscattering exceeding the GOCCP threshold or the ST threshold used at $1 / 3 \mathrm{~km}$ is assumed to be cloud. Depolarization and color ratio of $1 / 3-\mathrm{km}$ layers were studied to estimate the fraction of $1 / 3-\mathrm{km}$ layers that were dust and not cloud. Such misclassification was estimated to increase the global mean low cloud fraction by about 0.01. In active dust source regions, such as parts of the Sahara, the increase is estimated to be no more than 0.08 . 
(a) GOCCP

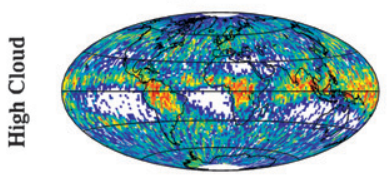

(e) GOCCP

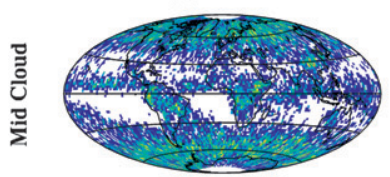

(i) GOCCP

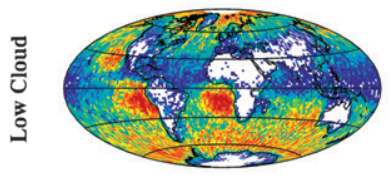

(b) $\mathrm{ST}$

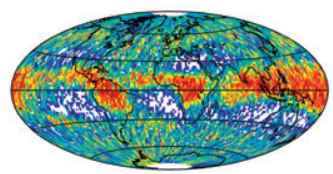

(f) ST

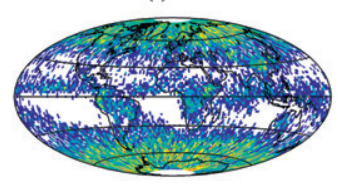

(j) ST

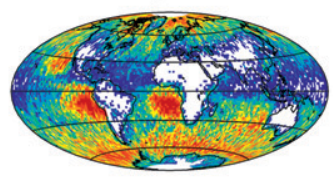

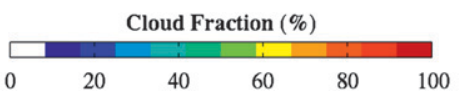

(c) ST - GOCCP

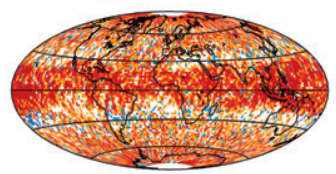

(g) ST - GOCCP

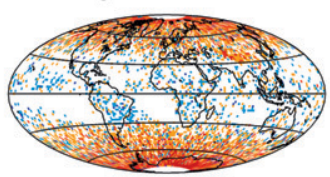

(k) ST - GOCCP

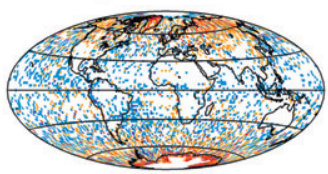

(d) ST - GOCCP

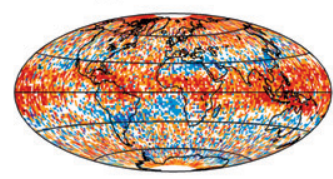

(h) ST - GOCCP

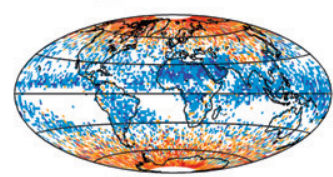

(l) ST - GOCCP
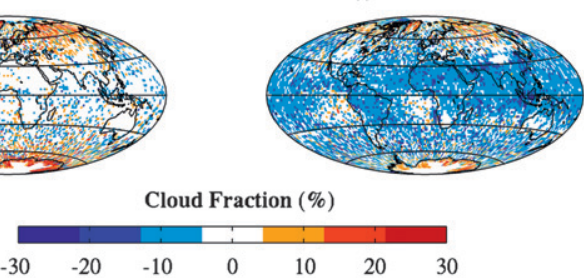

FIG. 6. Seasonal mean layered cloud fractions, SON 2006 (left) nighttime and (right) daytime. CALIPSO-GOCCP cloud fraction: (a) high level, (e) midlevel, and (i) low level. CALIPSO-ST cloud fraction: (b) high level, (f) midlevel, and (j) low level. Difference between ST and GOCCP cloud fractions during nighttime: (c) high level, (g) midlevel, and (k) low level. Difference between ST and GOCCP cloud fractions during day time: (d) high level, (h) midlevel, and (l) low level.

Analysis on a daytime orbit (not shown) exhibits results similar to nighttime.

\section{e. Polar clouds}

In both Arctic and Antarctic regions, ST observes more clouds than GOCCP, at all altitudes.

Figure 5 shows a typical Antarctic orbit where midlevel clouds (32\% in GOCCP and 77\% in ST) are likely associated with moderate SR (between 2 and 5; Fig. 5d), corresponding to optically thin clouds: they are classified as "uncertain" in GOCCP and "cloud" in ST. To examine this cloud type, GOCCP has been reprocessed for a lower detection threshold $(\mathrm{SR}=2$ and $\otimes \mathrm{ATB}=0$; see Fig. A1 in the appendix); the midlevel clouds are detected at smaller thresholds but with increased false detections. The presence of these optically thin polar ice clouds with a large vertical extent in the troposphere has been mentioned in previous studies (i.e., Grenier et al. 2009).

The same type of feature appears in the Arctic; the largest differences between the two datasets occur in midlevel clouds.

The polar regions, of both hemispheres, are characterized by the frequent occurrence of weakly scattering ice clouds, particularly during polar winter. These clouds are more often detected by ST than by GOCCP because of the lower detection thresholds of the ST algorithm.

\section{Global maps}

\section{a. Cloud maps}

Global maps of high, mid-, and low cloud fractions obtained with ST and GOCCP at night are presented in Fig. 6 (left and middle columns).

More high-level clouds are present in ST than GOCCP, consistent with the orbits studied in the previous section. The largest differences between the two datasets occur for high clouds in the tropical belt (Figs. $6 \mathrm{a}$ and $6 \mathrm{~b}$ ), where optically thin cirrus clouds are most often found (i.e., Martins et al. 2011; Sassen et al. 2009; Virts et al. 2010), are not detected by GOCCP, as explained previously. In daytime, above tropical stratocumulus, GOCCP detects more high clouds than ST (Fig. 6d, blue color), which is likely due to a smaller signal-to-noise ratio above $8 \mathrm{~km}$ of altitude (see section $2 \mathrm{~b}$ ), because of solar photon reflected on the stratocumulus clouds producing some false cloud detection at high altitude.

ST and GOCCP detect similar low-level cloud amounts in nighttime (Fig. 6k). In daytime (Fig. 61), GOCCP detect more low- and midlevel clouds because the cloud detection threshold used by GOCCP is smaller than the one used by ST (Fig. 1, single-shot threshold used for ST).

The polar areas are where ST and GOCCP cloud covers exhibit the largest differences (up to $+20 \%$ cloud cover) at all altitude levels (Fig. 7 for the Arctic 
(a) GOCCP

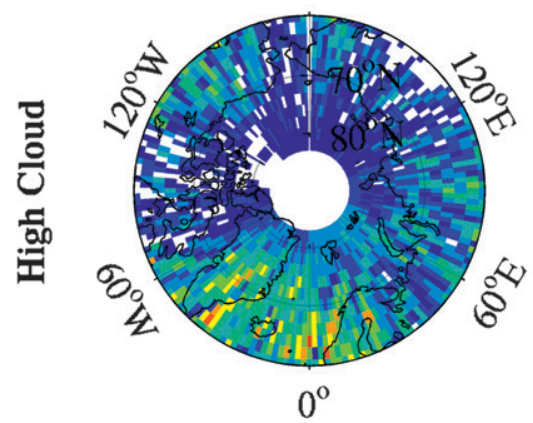

(d) GOCCP

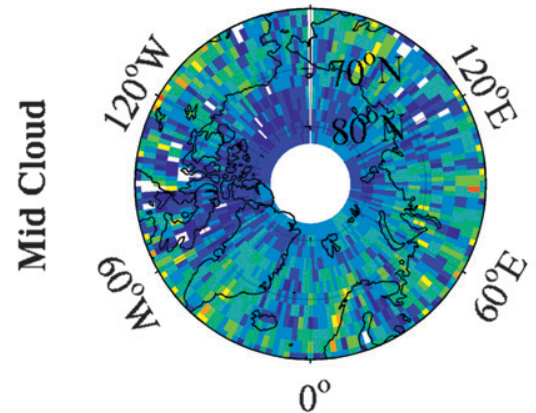

(g) GOCCP

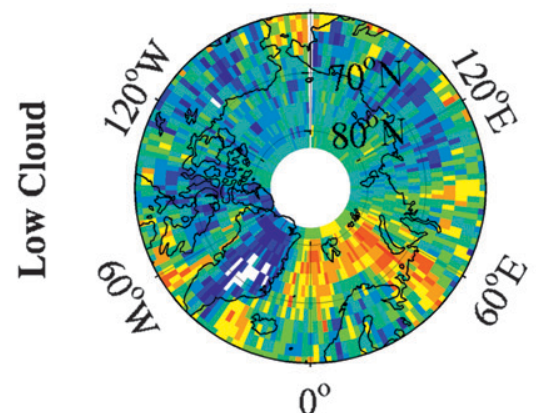

$0^{\circ}$ (b) ST

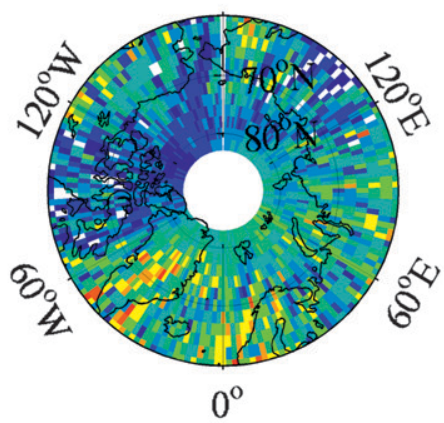

(e) ST

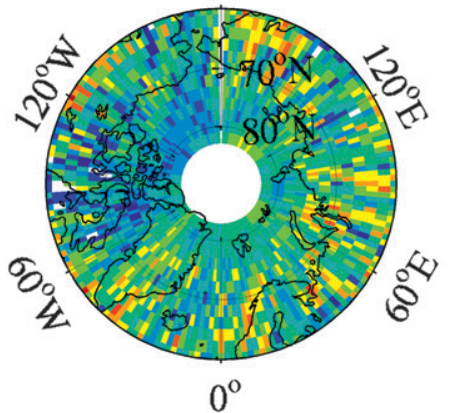

(h) ST

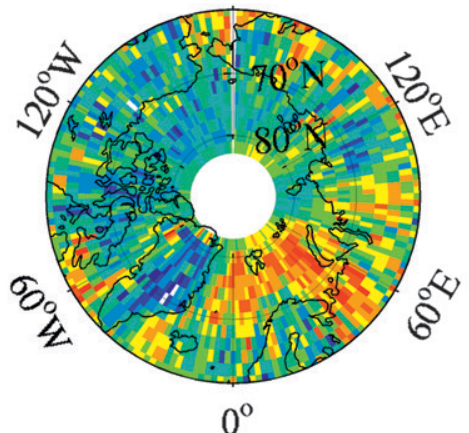

$0^{\circ}$

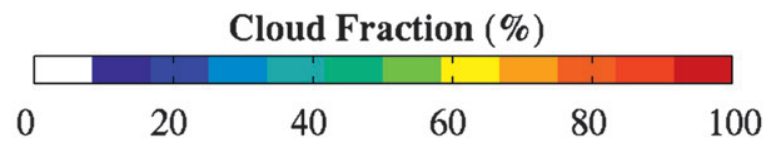

(c) ST - GOCCP

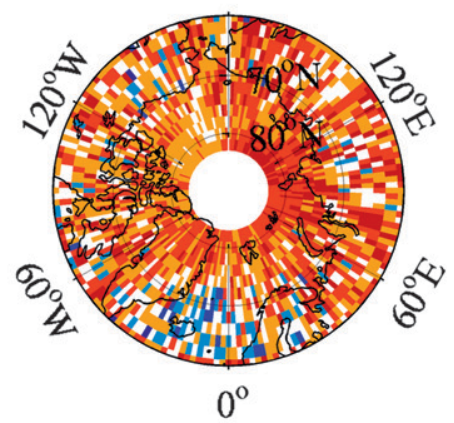

(f) ST - GOCCP

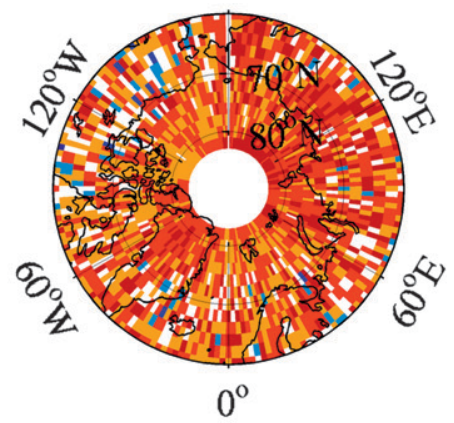

(i) ST - GOCCP

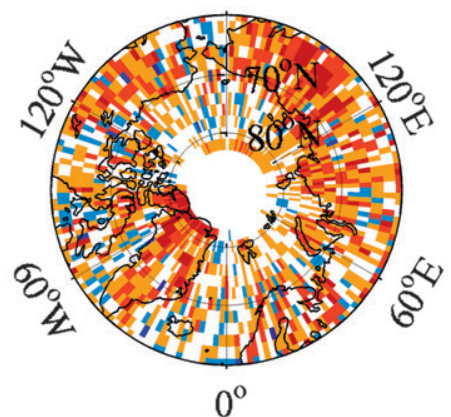

Cloud Fraction (\%)

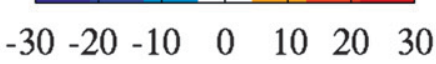

FIG. 7. Mean Arctic cloud cover, DJF 2006-07, nighttime. CF-high: (a) CALIPSO-GOCCP, (b) CALIPSO-ST, and (c) difference ST-GOCCP. CF-mid: (d) CALIPSO-GOCCP, (e) CALIPSO-ST, and (f) difference ST-GOCCP. CF-low: (g) CALIPSO-GOCCP, (h) CALIPSO-ST, and (i) difference ST-GOCCP.

and Fig. A2 for the Antarctic). In all cases, the ST cloud covers are larger than GOCCP, which is consistent with the orbit case studied (Fig. 5), showing that the differences are due to the optically thin clouds occurring in this region.

A quantitative evaluation (not shown) demonstrates that in the Arctic, the differences between ST and GOCCP are more pronounced during winter [DecemberFebruary (DJF) nighttime] than summer [June-August
(JJA) daytime] and that the differences are not dependent on the surface (land/ocean).

As GOCCP and ST maps of low, mid-, high clouds mostly differ in latitude and not in longitude, hereafter we study zonal means.

\section{b. Zonal means}

Low-level clouds from ST and GOCCP are consistent at all latitudes; GOCCP cloud fractions are 0.05 higher 
(a) ZONAL MEAN NIGHT TIME

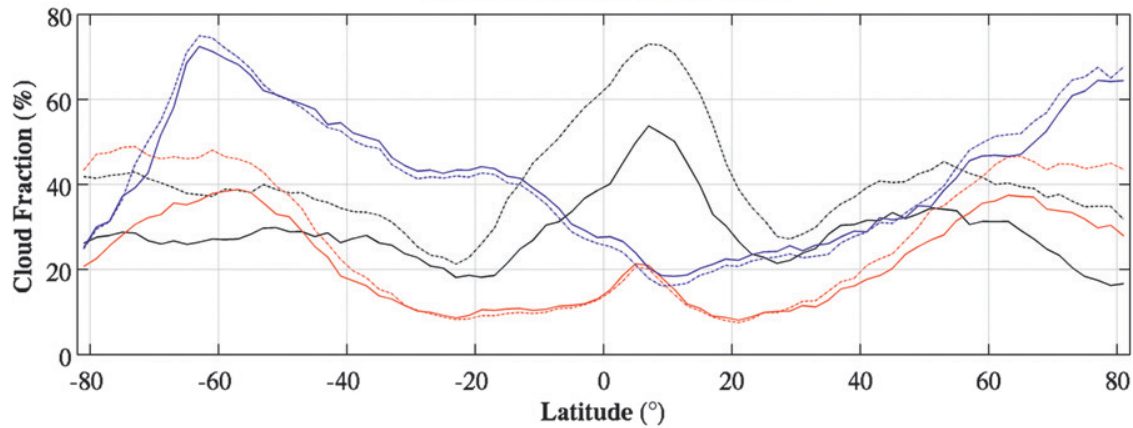

(b) ZONAL MEAN DAY TIME

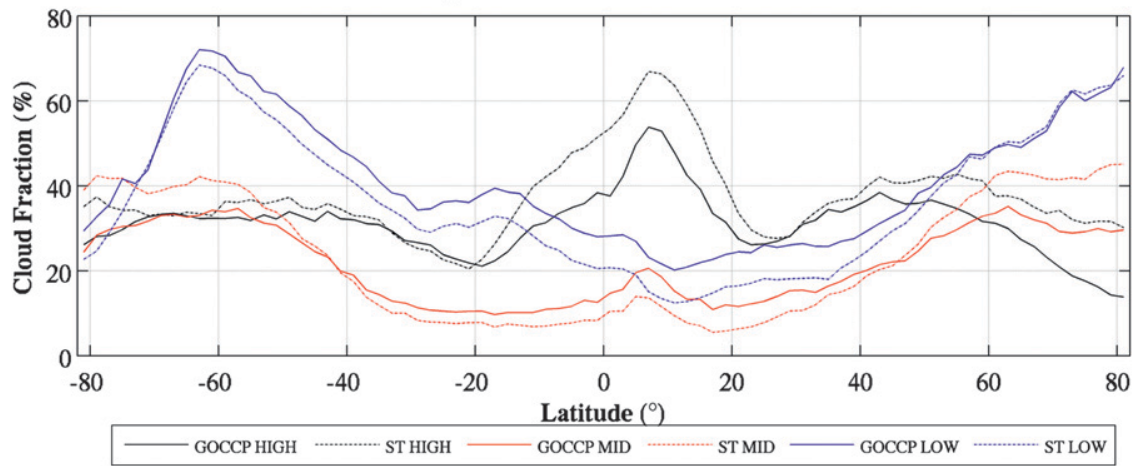

FIG. 8. Zonal mean of layered cloud fraction for CALIPSO-GOCCP and CALIPSO-ST. Lat/lon $\left(2^{\circ} \times 2^{\circ}\right)$, SON 2006. High-level clouds in black, midlevel clouds in red, and low-level clouds in blue: (a) nighttime and (b) daytime.

than ST in daytime (Fig. 8b), consistent with the orbit studied in Fig. 2 and with the difference in the cloud detection thresholds used in each algorithm (Fig. 1). Midlevel clouds show the largest differences in polar regions, consistent with the orbit studied in Fig. 5. In addition, the two datasets exhibit some differences in the tropics in daytime (Fig. 8b) that do not occur at night (Fig. 8a), in agreement with the change of the cloud detection used in ST between day and night (Fig. 1). High clouds exhibit large differences at all latitudes in both night and day, consistent with the orbit studied in Fig. 2.

The surface type (ocean or land; Fig. A3) below the cloud does not impact the differences between ST and GOCCP for high (Fig. A3a) and low (Fig. A3c) cloud covers (averaged over day and night): the differences between both datasets and their dependence on latitude are very similar above both ocean and land, suggesting that the surface does not introduce bias in the cloud detection in any of the datasets (especially for low-level clouds that are sometimes in contact with the surface).

For midlevel clouds, the differences between ST and GOCCP (Fig. A3b) in polar regions are similar above both land and sea surfaces.

\section{c. Summarized cloud fraction numbers}

Global high-, mid-, and low-level cloud cover is summarized in Table 1. On average, the two datasets give maximum cloud cover difference of 0.05 at low and midaltitudes, where GOCCP observes more optically thin clouds than ST. There are larger differences at high altitudes, where ST detects typically $10 \%$ more clouds than GOCCP, because of the increased presence of optically thin clouds.

In spite of the sparse sampling from the nadir-viewing CALIOP instrument, averaging to seasonal zonal scales provides robust statistics. Computing the statistics of Table 1 using only even days or only odd days over a 2-month period produces average even-day and odd-day cloud covers that agree within $0.5 \%$.

When examining specific regions (tropics, subtropics, polar regions), it appears that the largest differences between ST and GOCCP occur in polar regions during winter (Table 1): those differences (up to $+18 \%$ over land) are more pronounced in mid- and high-level altitudes, where the optically very thin cloud amount is significant and not reported in GOCCP. These differences occur for the same reasons in high-level tropical clouds, where subvisible clouds are frequent. 
TABLE 1. Average cloud cover reported in CALIPSO-ST and CALIPSO-GOCCP, mean percentage values (day + night).

\begin{tabular}{|c|c|c|c|c|c|c|}
\hline & \multicolumn{2}{|c|}{ Global } & \multicolumn{2}{|c|}{ OCEAN } & \multicolumn{2}{|c|}{ LAND } \\
\hline & GOCCP & ST & GOCCP & ST & GOCCP & ST \\
\hline \multicolumn{7}{|c|}{ All SON 2006} \\
\hline High & 31 & 40 & 30 & 39 & 33 & 41 \\
\hline Mid & 19 & 19 & 17 & 17 & 23 & 25 \\
\hline Low & 38 & 35 & 45 & 41 & 23 & 21 \\
\hline \multicolumn{7}{|c|}{ Tropics $\left(30^{\circ}-30^{\circ} \mathrm{S}\right)$, SON 2006} \\
\hline High & 32 & 44 & 31 & 42 & 37 & 47 \\
\hline Mid & 12 & 10 & 10 & 08 & 20 & 16 \\
\hline Low & 30 & 26 & 35 & 31 & 16 & 11 \\
\hline \multicolumn{7}{|c|}{ Midlatitude $\left(30^{\circ}-60^{\circ} \mathrm{N}, 30^{\circ}-60^{\circ} \mathrm{S}\right)$, SON 2006} \\
\hline High & 31 & 37 & 31 & 36 & 31 & 37 \\
\hline Mid & 22 & 25 & 22 & 24 & 23 & 25 \\
\hline Low & 44 & 41 & 52 & 49 & 23 & 21 \\
\hline \multicolumn{7}{|c|}{$\operatorname{Arctic}\left(60^{\circ}-90^{\circ} \mathrm{N}\right)$, SON 2006} \\
\hline High & 24 & 36 & 22 & 35 & 27 & 37 \\
\hline Mid & 33 & 44 & 31 & 42 & 35 & 45 \\
\hline Low & 54 & 57 & 65 & 65 & 46 & 51 \\
\hline \multicolumn{7}{|c|}{ Antarctic $\left(60^{\circ}-90^{\circ} \mathrm{S}\right), \mathrm{JJA} 2007$} \\
\hline High & 28 & 40 & 28 & 39 & 29 & 42 \\
\hline Mid & 30 & 45 & 32 & 45 & 26 & 45 \\
\hline Low & 50 & 49 & 62 & 62 & 26 & 29 \\
\hline
\end{tabular}

\section{Zonal cloud fraction profile}

The zonal cloud fraction profile is new, critical information provided by CALIPSO. It gives an unprecedented view of the detailed cloud vertical distribution, a new piece of knowledge that was missing in the puzzle of cloud observations.

This information was not possible to observe with passive instruments. These instruments derive the cloud vertical structure very indirectly compared to CALIPSO, which directly measures the distance between the satellite and the cloud. The zonal mean cloud fraction profile from ST and from GOCCP for day and night for September-November (SON) are reported in Fig. 9 at 480-m vertical resolution. The GOCCP zonal cloud fraction profile is lower than ST everywhere except at midlevels in the tropics and subtropics. The differences between the two datasets obtained in this season are representative of the others (not shown).

Contrary to the low-, mid-, and high-level cloud maps shown in previous sections, the zonal cloud fractions profile (Fig. 9) from GOCCP and ST are significantly different: the differences in cloud detection between the two datasets in each vertical layer (every $480 \mathrm{~m}$ ) directly impact the zonal cloud fraction profile, whereas it is not directly obvious on cloud maps. The cloud maps shown earlier contain several 480-m vertical levels (typically 7 in the low layer, 7 in the midlayer, and 26 in the high layer). The layer (low, middle, or high) is declared cloudy if one or more of the 480-m levels included in the layer is declared cloudy, whatever the altitude level and the number of cloudy levels within the layer. As a consequence, very different cloud distributions within the 480-m levels included within a layer can produce similar maps of low (or middle or high) cloud; for example, a low cloud layer will be declared cloudy if all seven successive vertical 480-m levels included in the layer are cloudy, or if only one of the seven levels is declared cloudy. But, unlike the cloud map, the zonal cloud fraction profile associated with these two scenarios will look very different. This effect is illustrated in Fig. 4: the vertical extent of ST high clouds $(z>8 \mathrm{~km})$ is larger than the GOCCP one.

The differences between the zonal cloud fraction profile in ST and GOCCP in different regions (boundary layer clouds, high clouds, tropics, midlatitudes, polar regions) in Fig. 9 have various reasons because they are mostly induced by the types of cloud observed (vertical and horizontal extension, cloud optical depth). To understand the source of the differences between ST and GOCCP, we use case studies (section 3) and examine the sensitivity of the zonal cloud fraction profile to the three parameters involved in the cloud detection: SR threshold, and horizontal and vertical averaging of the lidar profile before the cloud detection.

The large difference between day and night in the ST zonal cloud fraction profile (Figs. 9a and 9c) demonstrates that sensitivity differences at the low SR values are important. Consistently, the GOCCP zonal cloud fraction profile is similar in day and night (Figs. 9b and 9d) because it is using a constant spatial resolution and a single cloud detection threshold.

\section{a. Vertical resolution}

ST and GOCCP detect clouds at different vertical resolutions: GOCCP performs cloud detection on SR profiles with $480-\mathrm{m}$ vertical resolution, whereas ST performs it on SR profiles with 30 - or $60-\mathrm{m}$ vertical resolution. To examine the impact of this difference, we computed the GOCCP zonal cloud fraction profile for different vertical resolutions (240 and $120 \mathrm{~m}$ ). The resulting changes in low-, mid-, high-level clouds (not shown) were too small to explain the difference between ST and GOCCP.

\section{b. Cloud detection threshold}

The threshold of cloud detection is lower in ST than in GOCCP (see Fig. 1), implying that ST detects clouds with lower optical depth than GOCCP. We processed the GOCCP zonal cloud fraction profile with a lower detection threshold $(\mathrm{SR}=2, \otimes \mathrm{ATB}=0$ instead of $\mathrm{SR}=5$ ) during nighttime (when the SNR is higher because of the absence of solar photons) to examine 
(a) CF3D ST NIGHT

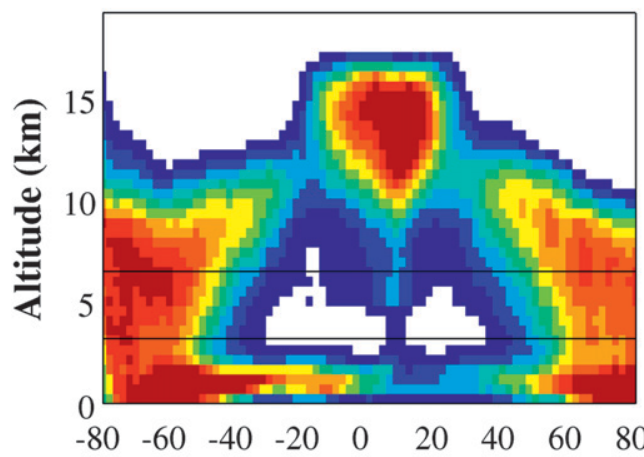

(c) CF3D ST DAY

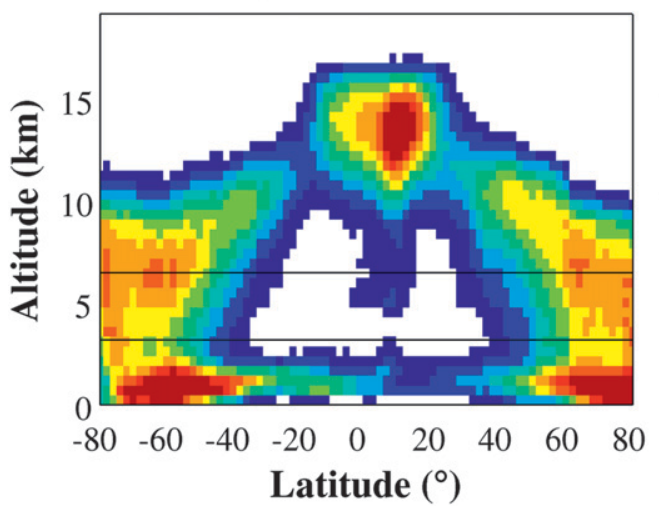

(b) CF3D GOCCP NIGHT

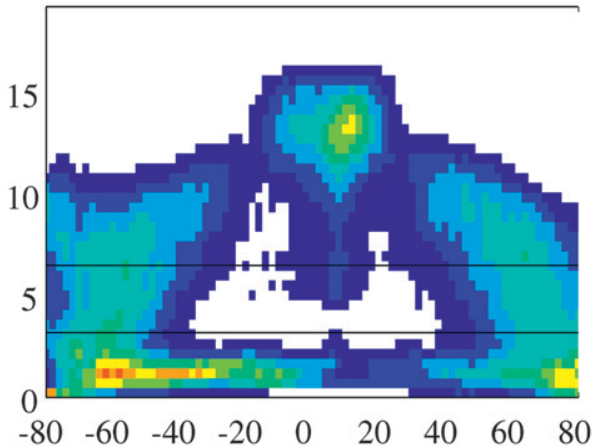

(d) CF3D GOCCP DAY

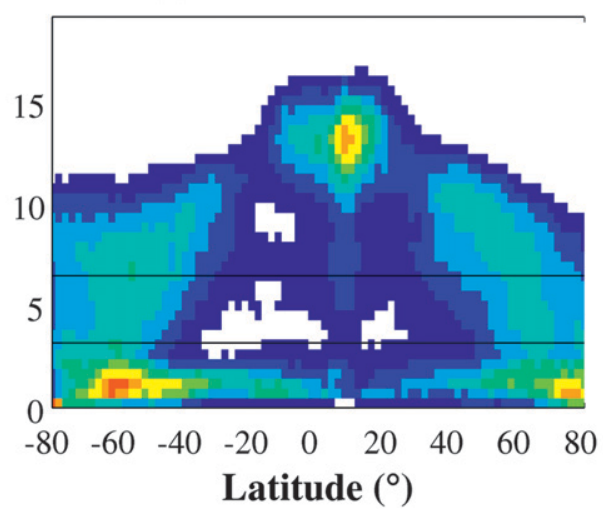

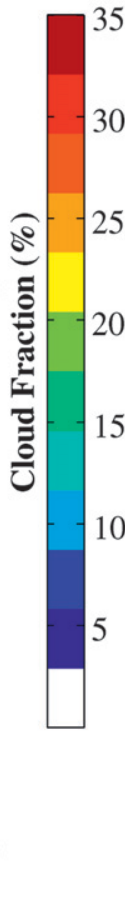

FIG. 9. Zonal mean cloud fraction profile for SON 2006, lat/lon $\left(2^{\circ} \times 2^{\circ}\right)$, and 40 vertical levels $(480 \mathrm{~m})$. (a) CF3D CALIPSO-ST nighttime. (b) CF3D CALIPSO-GOCCP (standard), nighttime, $\Delta x=330 \mathrm{~m}, \mathrm{SR}=5, \Delta \mathrm{ATB}=2.5 \times$ $10^{-3} \mathrm{~km}^{-1} \mathrm{sr}^{-1}$. (c) CF3D CALIPSO-ST, daytime. (d) CF3D CALIPSO-GOCCP (standard), daytime, $\Delta x=330 \mathrm{~m}$, $\mathrm{SR}=5, \Delta \mathrm{ATB}=2.5 \times 10^{-3} \mathrm{~km}^{-1} \mathrm{sr}^{-1}$.

whether this can explain differences between GOCCP and ST. Figure 10a shows that the GOCCP cloud fraction profile is increased at all altitudes and latitudes when the cloud detection threshold is reduced. GOCCP still detects less than ST in the tropical upper troposphere, in the boundary layer, and throughout the troposphere in the polar regions. Moreover, polar stratospheric clouds (having small optical depths) show up over Antarctica but false detections occur below $8 \mathrm{~km}$ of altitude, where the SNR is lower because there is no horizontal averaging done on board a satellite below $8 \mathrm{~km}(1 / 3 \mathrm{~km}$ below $8 \mathrm{~km}$ and $1 \mathrm{~km}$ above).

Nevertheless, despite the lower detection threshold used in GOCCP-SR2, the zonal mean cloud fraction from ST remains greater (Fig. 10b) in most of the cloudy regions. When averaging over $80 \mathrm{~km}$ (Fig. 10d), the difference between ST and GOCCP is reduced; however, some optically thin clouds are still detected by ST only in the upper troposphere. Based on Fig. 1, the remaining clouds have an optical depth lower than 0.017 $(\mathrm{SR}<2)$.

\section{c. Horizontal resolution}

The horizontal resolution used in GOCCP is equal to $1 / 3 \mathrm{~km}$. On the other hand, ST performs cloud detection at different horizontal resolutions between $1 / 3$ and $80 \mathrm{~km}$, depending on the amount of averaging required to detect the cloud. For testing the sensitivity of the results to the horizontal averaging, we processed GOCCP-SR2 by averaging the lidar profile over $80 \mathrm{~km}$ along the orbit track before doing cloud detection.

The zonal cloud fraction profile increases significantly everywhere (Fig. 10c), in particular in boundary layer clouds, where a small-size cumulus cloud (typically $500 \mathrm{~m}$ ) surrounded by clear air will produce a large SR value (because it scatters strongly) at $1 / 3-\mathrm{km}$ horizontal resolution and be detected as one small cloud (with $1 / 3-\mathrm{km}$ extent) surrounded by a cloud-free area. When averaged over $80-\mathrm{km}$ horizontal resolution, however, this same cloud of $1 / 3-\mathrm{km}$ size will still be detected (because the $80-\mathrm{km}$ horizontally averaged SR value will be larger than 2) but the entire $80 \mathrm{~km}$ will be considered 
(a) CF3D GOCCP(SR2)

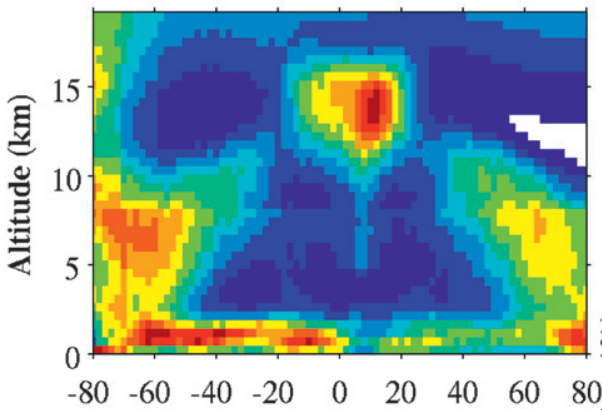

(c) CF3D GOCCP (SR2-80km)

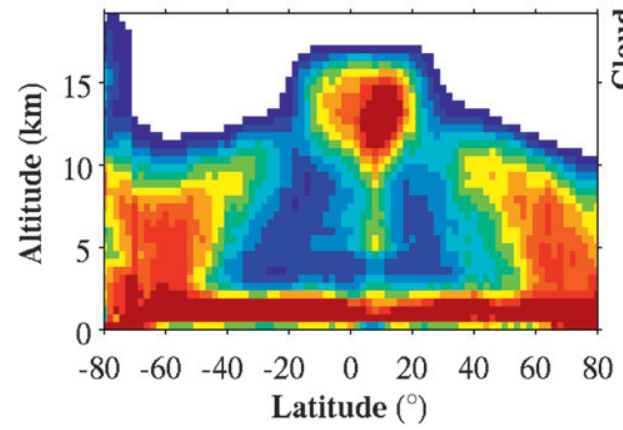

(b) CF3D ST - GOCCP(SR2)

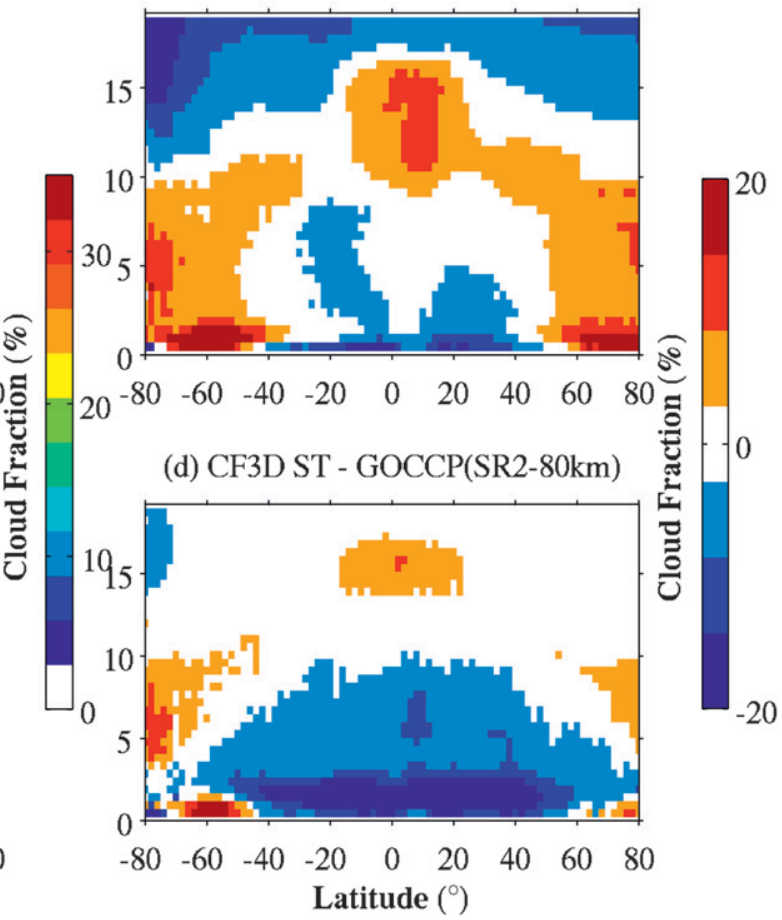

FIG. 10. Zonal mean cloud fraction profile (CF3D) for SON 2006, nighttime, lat/lon $\left(2^{\circ} \times 2^{\circ}\right)$, and 40 vertical levels $(480 \mathrm{~m})$. (a) CF3D CALIPSO-GOCCP-test1, NOT standard: $\Delta x=330 \mathrm{~m}, \mathrm{SR}=2, \Delta \mathrm{ATB}=0$. (b) CF3D CALIPSOST - CALIPSO-GOCCP-test1. (c) CF3D CALIPSO-GOCCP-test2, NOT standard: $\Delta x=80 \mathrm{~km}, \mathrm{SR}=2, \Delta \mathrm{ATB}=0$. (d) CF3D CALIPSO-ST - CALIPSO-GOCCP-test2.

cloudy, even if only a very small fraction of it is actually cloudy. This effect artificially increases the cloud cover retrieved in regions with broken clouds such as shallow cumulus, frequently encountered in the boundary layer. When the clouds are homogeneous over a very large extent $(80 \mathrm{~km})$, as with some cirrus clouds, for example, the horizontal averaging increases the SNR and allows better detection of optically very thin clouds.

The additional averaging applied to ST improves the agreement between ST and GOCCP-SR2 and the 80-km zonal cloud fraction profile in the upper troposphere (Fig. 10d vs Fig. 10a), although GOCCP now overestimates cloud fraction relative to ST at middle and low altitudes. Figure 10 illustrates that most of the differences between the two datasets comes from the horizontal resolutions and the cloud detection thresholds used-two parameters that cannot be considered fully independently (except in sensitivity studies like here) as both of them depend on the SNR: (i) using high cloud detection thresholds ensures safe cloud detection and limits false positives but implies losing some optically thin clouds and (ii) reducing the threshold to detect optically thin clouds is meaningful only if the SNR is sufficient, otherwise it will produce false positives.
Ideally, the cloud detection (defined by the amount of horizontal averaging along the orbit track before cloud detection and the cloud detection threshold) should be adapted to each cloud scene individually, which is not doable because the cloud characteristics are a priori unknown. The ST algorithm was designed to be as close as possible to this approach. On the other hand, GOCCP has a fixed constant horizontal resolution $(1 / 3 \mathrm{~km})$ and a fixed detection threshold.

\section{Conclusions}

This paper aims to understand the differences between cloud cover and vertical distribution obtained from the same CALIPSO-attenuated backscattered profile dataset (level 1) using two different algorithms, referred to as ST and GOCCP, that have been built with different objectives. The first one was developed by the CALIPSO Science Team and aims at documenting all types of clouds as well as possible. The second is built to be consistent with the lidar simulator included in the COSP package and to evaluate cloudiness in climate models.

CALIPSO daytime and nighttime orbits containing typical cloud scenes (boundary layer shallow cumulus, 
cirrus, midlevel tropical clouds, etc.) were first examined to characterize the detailed cloud picture produced by each algorithm, and to point out the main differences: ST detects more clouds than GOCCP, particularly at high altitudes and in the polar regions, where the clouds are often optically thin (typically cirrus clouds with optical depth lower than 0.07 are not detected by GOCCP in the upper troposphere).

Comparison shows differences in the global cloud cover maps from the two algorithms are frequently larger than $10 \%$ and vary with region (e.g., Arctic versus tropics, day versus night, high-level versus midlevel cloud amounts). The low-, mid-, and high-level cloud covers are also dependent on the algorithm mostly in the polar regions, where the maximum difference is encountered $(15 \%)$.

Both algorithms produce a low-level cloud cover larger than previously observed by passive remote sensors. Still, the actual low-level cloud cover is likely even larger in specific regions, such as the midlatitude storm track and the along the intertropical convergence zone, because of the attenuation of the lidar signal when passing through upper-altitude clouds.

Larger differences between the two datasets show up in the zonal cloud fraction profile, which is a new variable that was not observed from space before CALIPSO and CloudSat. Before, the vertical cloud distribution was obtained very indirectly from passive remote sensors at coarse vertical resolution and with large uncertainties (Weisz et al. 2007; Holz et al. 2008; Kahn et al. 2008; Minnis et al. 2008). The zonal cloud fraction profile obtained by ST and GOCCP are compared at 480-m vertical resolution and are found to differ by a factor of almost 2 in some regions, the ST zonal cloud fraction profile being always larger than GOCCP. Moreover, ST shows significant day-night differences contrarily to GOCCP cloud fraction profiles that are very similar during the day and night. A sensitivity study using various cloud detection thresholds and different horizontal and vertical averaging before cloud detection has been conducted to understand the reasons for the differences between the zonal cloud fraction profile in ST and
GOCCP. The zonal cloud fraction profile is highly sensitive to both the cloud detection threshold and the horizontal averaging. Horizontal averaging over long distances (up to $80 \mathrm{~km}$ ) allows for detecting high-altitude optically thin clouds that are not detected otherwise, and it explains most of the differences between the two datasets. Nevertheless, applying such large horizontal averaging at low altitudes can artificially increase the cloud cover in the low troposphere.

The differences between the two datasets are now well understood and are mostly due to the different horizontal averaging and cloud detection thresholds used in the two algorithms. We recommend using the CALIPSOGOCCP dataset for climate model evaluation purposes through the COSP simulator: the horizontal resolution $(1 / 3 \mathrm{~km})$ and the cloud detection threshold $(\mathrm{SR}=5)$ are fixed in GOCCP. We recommend using the CALIPSO-ST dataset for other cloud analyses and choosing carefully the horizontal resolution based on the optical depth of clouds under study.

The CALIPSO-GOCCP datasets are available online (http://climserv.ipsl.polytechnique.fr/cfmip-obs/). The CALIPSO-ST dataset is available on the NASA Langley Atmospheric Sciences Data Center website (http:// eosweb.larc.nasa.gov).

Acknowledgments. We thank the three anonymous reviewers, who helped us improve the manuscript significantly. Thanks are due to NASA and CNES for CALIOP level 1 data. We thank Vincent Noel and Jean Louis Dufresne for the internal review, the CGTD/ ICARE for access level 1 data, and CLIMSERV/ICARE for access to the computing facility.

\section{APPENDIX}

\section{Antarctic Clouds (Detection and Cloud Cover), and Comparisons between Land and Ocean Cloud Covers}

Figures A1, A2, and A3 are shown below. 
(a) GOCCP Scattering Ratio

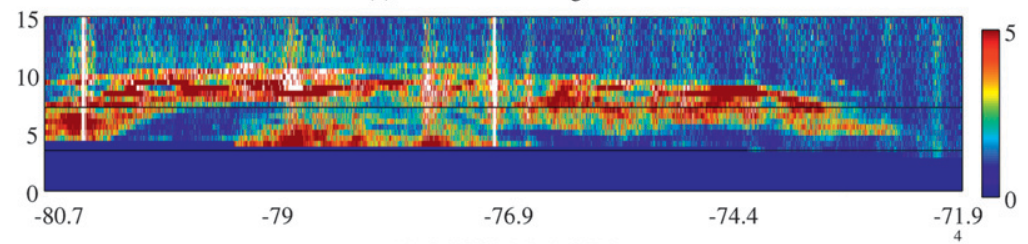

(b) GOCCP Mask SR5

$x 10$
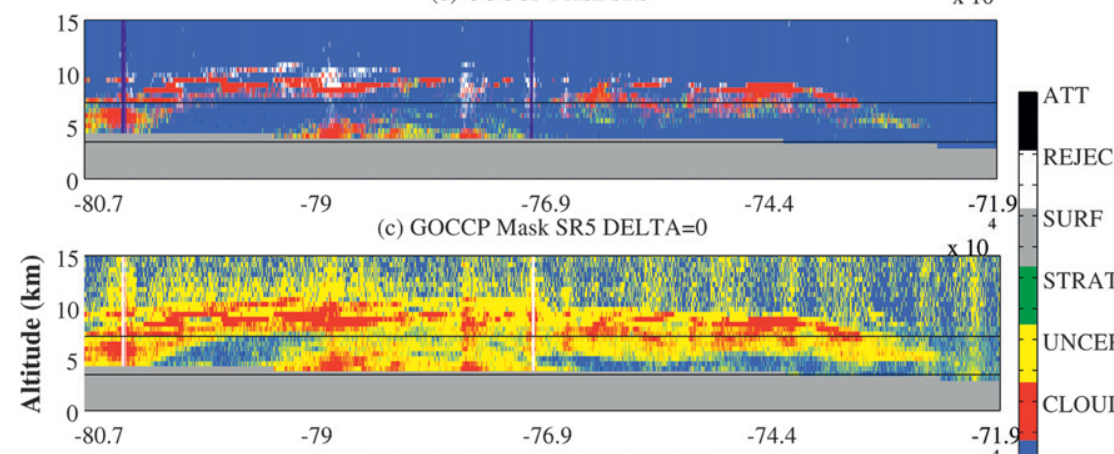

STRATO

(d) GOCCP Mask SR2 DELTA=0

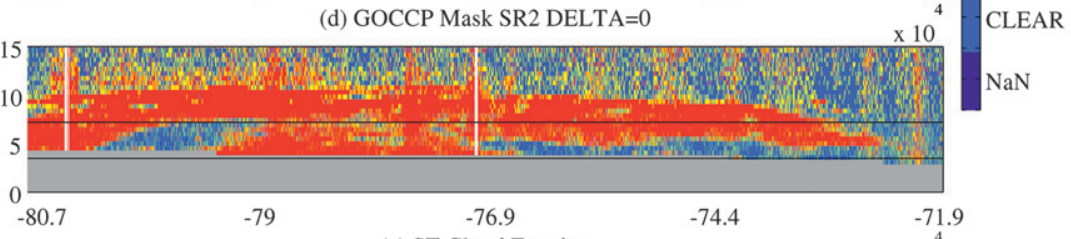

(e) ST Cloud Fraction

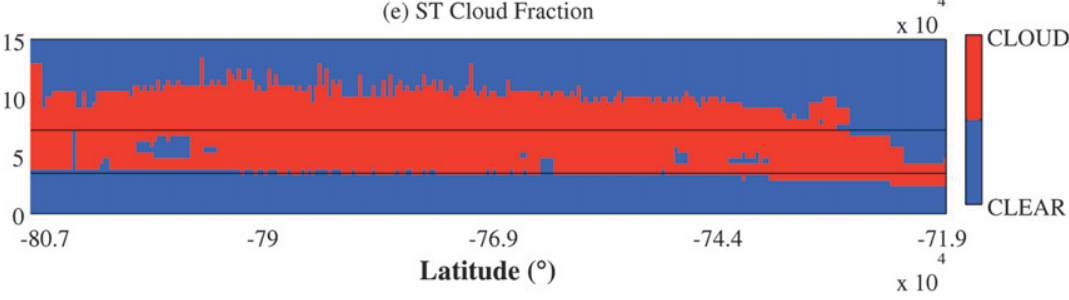

FIG. A1. Sensitivity to the cloud detection threshold over Antarctica, vertical resolution $480 \mathrm{~m}$ : (a)-(d) CALIPSO-GOCCP, (e) CALIPSO-ST. (a) Scattering ratio (white pixels correspond to $\mathrm{SR}<5$ and $\triangle \mathrm{ATB}<2.5 \times 10^{-3} \mathrm{~km}^{-1} \mathrm{sr}^{-1}$ ). (b) Cloud mask for standard detection: SR $>5$ and $\Delta \mathrm{ATB}>2.5 \times 10^{-3} \mathrm{~km}^{-1} \mathrm{sr}^{-1}$. (c) Cloud mask; pixels are flagged cloudy when SR $>5$. (d) Cloud mask; pixels are flagged cloudy when SR $>2$. 


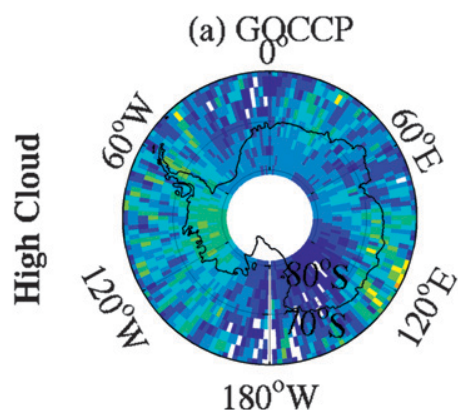

(d) GgCCP

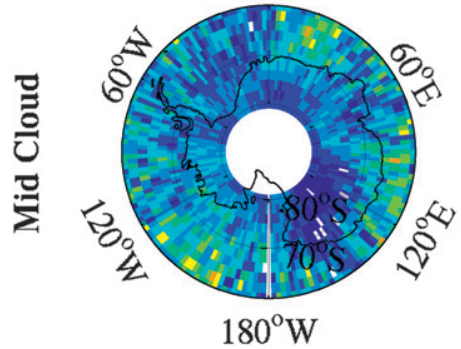

(g) GgCCP

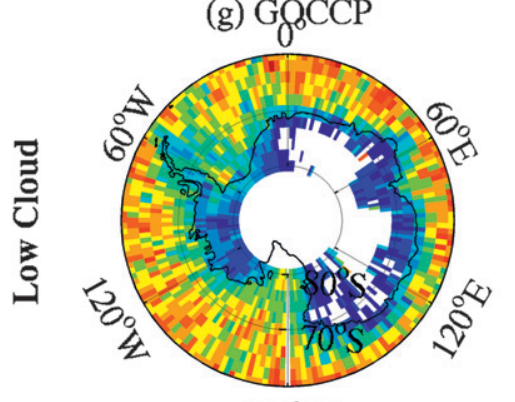

$180^{\circ} \mathrm{W}$
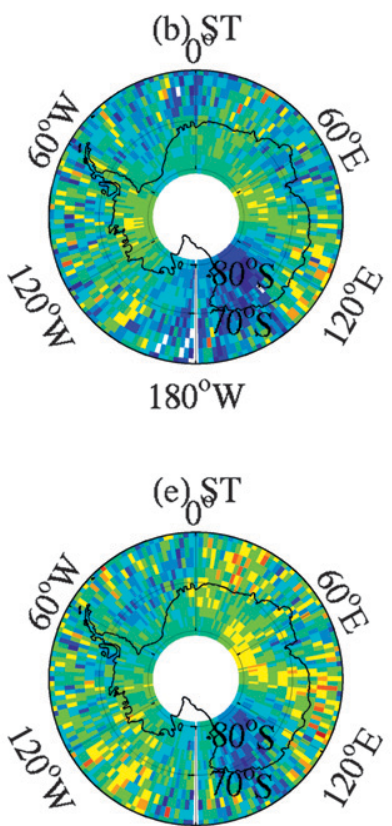

$180^{\circ} \mathrm{W}$

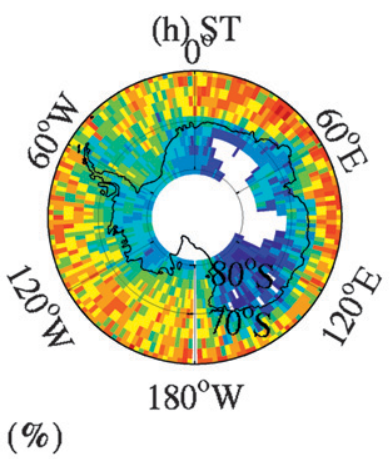

Cloud Fraction (\%)

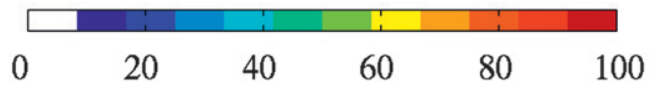

(c) $\mathrm{ST}-\mathrm{GOCCP}$

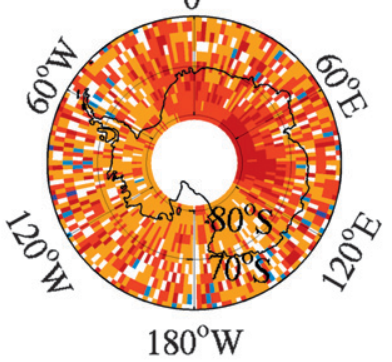

(f) $\mathrm{ST}-0 \mathrm{GOCCP}$

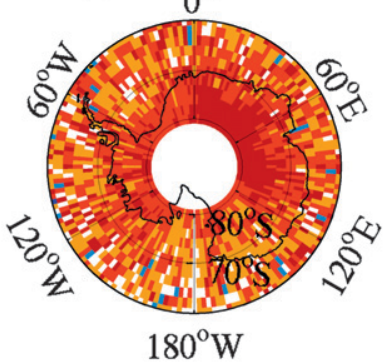

(i) $\mathrm{ST}-\mathrm{GOCCP}$

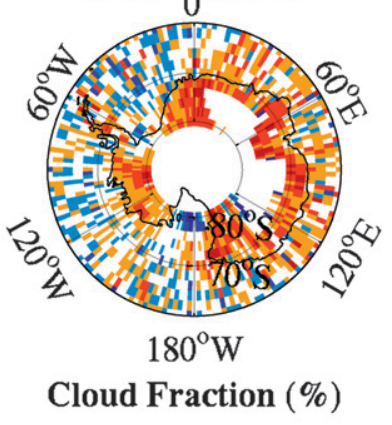

$\begin{array}{lllllll}-30 & -20 & -10 & 0 & 10 & 20 & 30\end{array}$

FIG. A2. As in Fig. 7, but for Antarctica in JJA. 
(a) High Cloud

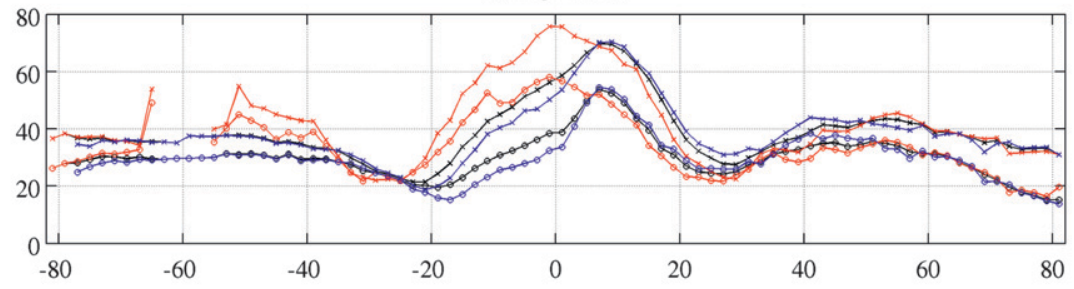

(b) Middle Cloud
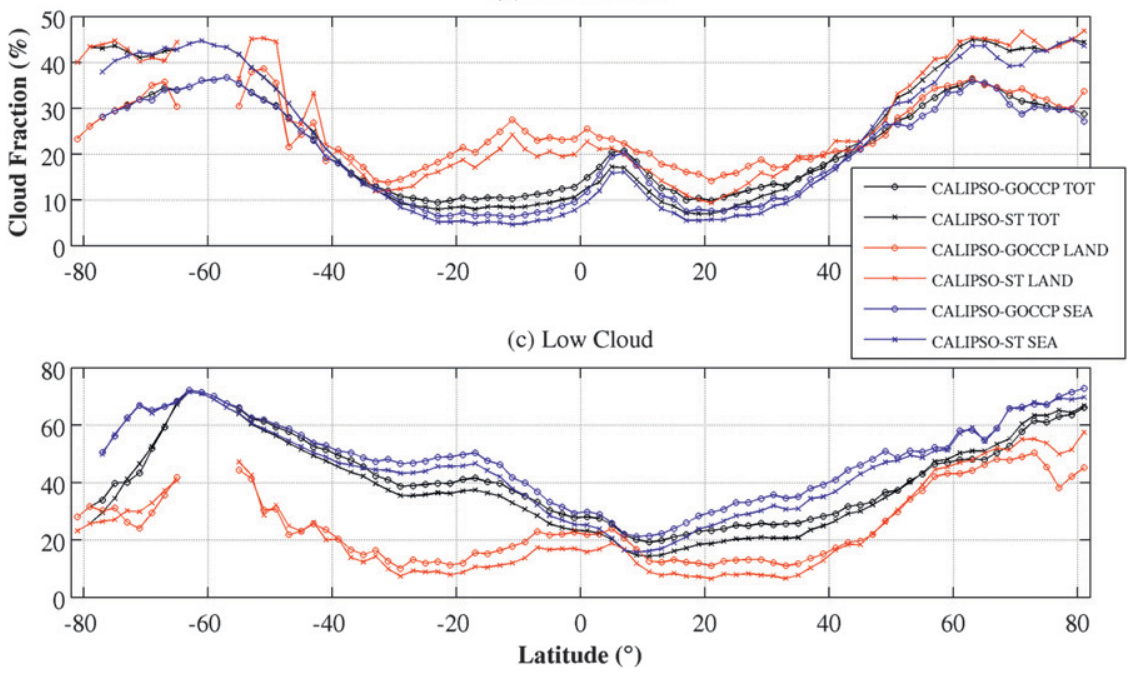

FIG. A3. Zonal mean of layered cloud fraction for CALIPSO-GOCCP (line $+\mathrm{o}$ ) and CALIPSO-ST (line $+\mathrm{x}$ ) over ocean (in blue), and over land surface (in red) and sea + land (in black), averaged over daytime and nighttime, lat/lon $\left(2^{\circ} \times 2^{\circ}\right)$, for SON 2006: (a) high-level, (b) midlevel, and (c) low-level cloud fraction.

\section{REFERENCES}

Bodas-Salcedo, A., M. J. Webb, M. E. Brooks, M. A. Ringer, K. D. Williams, S. F. Milton, and D. R. Wilson, 2008: Evaluating cloud systems in the Met Office global forecast model using simulated CloudSat radar reflectivities. J. Geophys. Res., 113, D00A13, doi:10.1029/2007JD009620.

_ , and Coauthors, 2011: COSP: Satellite simulation software for model assessment. Bull. Amer. Meteor. Soc., 92, 1023-1043

Chepfer, H., S. Bony, D. M. Winker, M. Chiriaco, J.-L. Dufresne, and G. Sèze, 2008: Use of CALIPSO lidar observations to evaluate the cloudiness simulated by a climate model. Geophys. Res. Lett., 35, L15704, doi:10.1029/2008GL034207.

$\longrightarrow,-$, D. Winker, G. Cesana, J.-L. Dufresne, P. Minnis, C. J. Stubenrauch, and S. Zeng, 2010: The GCM-oriented CALIPSO Cloud Product (CALIPSO-GOCCP). J. Geophys. Res., 115, D00H16, doi:10.1029/2009JD012251.

Davis, S. M., and Coauthors, 2010: In situ and lidar observations of tropopause subvisible cirrus clouds during TC4. J. Geophys. Res., 115, D00J17, doi:10.1029/2009JD013093.

Deuzé, J.-L., and Coauthors, 2001: Remote sensing of aerosols over land surfaces from POLDER-ADEOS-1 polarized measurements. J. Geophys. Res., 106 (D5), 4913-4926.

Grenier, P., J.-P. Blanchet, and R. Muñoz-Alpizar, 2009: Study of polar thin ice clouds and aerosols seen by CloudSat and CALIPSO during midwinter 2007. J. Geophys. Res., 114, D09201, doi:10.1029/2008JD010927.
Holz, R. E., S. A. Ackerman, F. W. Nagle, R. Frey, S. Dutcher, R. E. Kuehn, M. A. Vaughan, and B. Baum, 2008: Global Moderate Resolution Imaging Spectroradiometer (MODIS) cloud detection and height evaluation using CALIOP. J. Geophys. Res., 113, D00A19, doi:10.1029/2008JD009837.

Hunt, W. H., D. M. Winker, M. A. Vaughan, K. A. Powell, P. L. Lucker, and C. Weimer, 2009: CALIPSO lidar description and performance assessment. J. Atmos. Oceanic Technol., 26, 1214-1228.

Kahn, B. H., and Coauthors, 2008: Cloud type comparisons of AIRS, CloudSat, and CALIPSO cloud height and amount. Atmos. Chem. Phys., 8, 1231-1248, doi:10.5194/acp-8-1231-2008.

Klein, S. A., and C. Jakob, 1999: Validation and sensitivities of frontal clouds simulated by the ECMWF model. Mon. Wea. Rev., 127, 2514-2531.

Liu, Z., M. A. Vaughan, D. M. Winker, C. Kittaka, R. E. Kuehn, B. J. Getzewich, C. R. Trepte, and C. A. Hostetler, 2009: The CALIPSO lidar cloud and aerosol discrimination: Version 2 algorithm and initial assessment of performance. J. Atmos. Oceanic Technol., 26, 1198-1213.

Marchand, R., J. Haynes, G. G. Mace, T. Ackerman, and G. Stephens, 2009: A comparison of simulated cloud radar output from the multiscale modeling framework global climate model with CloudSat cloud radar observations. J. Geophys. Res., 114, D00A20, doi:10.1029/2008JD009790.

Martins, E., V. Noel, and H. Chepfer, 2011: Properties of cirrus and subvisible cirrus from nighttime Cloud-Aerosol Lidar with 
Orthogonal Polarization (CALIOP), related to atmospheric dynamics and water vapor. J. Geophys. Res., 116, D02208, doi:10.1029/2010JD014519.

McGill, M. J., M. A. Vaughan, C. R. Trepte, W. D. Hart, D. L. Hlavka, D. M. Winker, and R. Kuehn, 2007: Airborne validation of spatial properties measured by the CALIPSO lidar. J. Geophys. Res., 112, D20201, doi:10.1029/2007JD008768.

Medeiros, B., L. Nuijens, C. Antoniazzi, and B. Stevens, 2010: Lowlatitude boundary layer clouds as seen by CALIPSO. J. Geophys. Res., 115, D23207, doi:10.1029/2010JD014437.

Minnis, P., and Coauthors, 2008: Cloud detection in nonpolar regions for CERES using TRMM VIRS and Terra and Aqua MODIS data. IEEE Trans. Geosci. Remote Sens., 46, $3857-$ 3884, doi:10.1109/TGRS.2008.2001351.

Noel, V., A. Hertzog, H. Chepfer, and D. M. Winker, 2008: Polar stratospheric clouds over Antarctica from the CALIPSO spaceborne lidar. J. Geophys. Res., 113, D02205, doi:10.1029/ 2007JD008616.

- - , and — 2009: CALIPSO observations of waveinduced PSCs with near-unity optical depth over Antarctica in 2006-2007. J. Geophys. Res., 114, D05202, doi:10.1029/ 2008JD010604.

Parol, F., and Coauthors, 2004: Capabilities of multi-angle polarization cloud measurements from satellite: POLDER results. Adv. Space Res., 33, 1080-1088.

Pitts, M. C., L. W. Thomason, L. R. Poole, and D. M. Winker, 2007: Characterization of polar stratospheric clouds with spaceborne lidar: CALIPSO and the 2006 Antarctic season. Atmos. Chem. Phys., 7, 5207-5228, doi:10.5194/acp-7-5207-2007.

Platnick, S., M. D. King, S. A. Ackerman, W. P. Menzel, B. A. Baum, J. C. Riedi, and R. A. Frey, 2003: The MODIS cloud products: Algorithms and examples from Terra. IEEE Trans. Geosci. Remote Sens., 41, 459-473.

Rossow, W. B., and R. A. Schiffer, 1999: Advances in understanding clouds from ISCCP. Bull. Amer. Meteor. Soc., 80, 2261-2287.

Sassen, K., Z. Wang, and D. Liu, 2009: Cirrus clouds and deep convection in the tropics: Insights from CALIPSO and CloudSat. J. Geophys. Res., 114, D00H06, doi:10.1029/2009JD011916.

Stephens, G. L., and Coauthors, 2002: The CloudSat mission and the A-train. Bull. Amer. Meteor. Soc., 83, 1771-1790.

Stubenrauch, C. J., W. B. Rossow, N. A. Scott, and A. Chédin, 1999: Clouds as seen by infrared sounders (3I) and imagers (ISCCP). Part III: Spatial heterogeneity and radiative effects. J. Climate, 12, 3419-3442.

, A. Chédin, G. Rädel, N. A. Scott, and S. Serrar, 2006: Cloud properties and their seasonal and diurnal variability from TOVS Path-B. J. Climate, 19, 5531-5553.
_ W. Wossow, and S. Kinne, 2012: Assessment of global cloud data sets from satellites. WCRP Rep. 23/2012, 176 pp.

Thorsen, T. J., Q. Fu, and J. M. Comstock, 2011: Comparison of the CALIPSO satellite and ground-based observations of cirrus clouds at the ARM TWP sites. J. Geophys. Res., 116, D21203, doi:10.1029/2011JD015970.

Vaughan, M., and Coauthors, 2009: Fully automated detection of cloud and aerosol layers in the CALIPSO lidar measurements. J. Atmos. Oceanic Technol., 26, 2034-2050.

Virts, K. S., J. M. Wallace, Q. Fu, and T. P. Ackerman, 2010: Tropical tropopause transition layer cirrus as represented by CALIPSO lidar observations. J. Atmos. Sci., 67, 31133129.

Webb, M., C. Senior, S. Bony, and J. J. Morcrette, 2001: Combining ERBE and ISCCP data to assess clouds in the Hadley Centre, ECMWF and LMD atmospheric climate models. Climate Dyn., 17, 905-922.

Weisz, E., J. Li, W. P. Menzel, A. K. Heidinger, B. H. Kahn, and C.-Y. Liu, 2007: Comparison of AIRS, MODIS, CloudSat and CALIPSO cloud top height retrievals. Geophys. Res. Lett., 34, L17811, doi:10.1029/2007GL030676.

Winker, D. M., and C. R. Trepte, 1998: Laminar cirrus observed near the tropical tropopause by LITE. Geophys. Res. Lett., $\mathbf{2 5}$, 3351-3354.

- W. H. Hunt, and M. J. McGill, 2007: Initial performance assessment of CALIOP. Geophys. Res. Lett., 34, L19803, doi:10.1029/2007GL030135.

—, M. A. Vaughan, A. H. Omar, Y. Hu, K. A. Powell, Z. Liu, W. H. Hunt, and S. A. Young, 2009: Overview of the CALIPSO mission and CALIOP data processing algorithms. J. Atmos. Oceanic Technol., 26, 2310-2323.

— , and Coauthors, 2010: The CALIPSO mission: A global 3D view of aerosols and clouds. Bull. Amer. Meteor. Soc., 91, 1211-1229.

Yorks, J. E., D. L. Hlavka, M. J. Vaughan, M. J. McGill, W. D. Hart, S. Rodier, and R. Kuehn, 2011: Airborne validation of cirrus cloud properties derived from CALIPSO lidar measurements: Spatial properties. J. Geophys. Res., 116, D19207, doi:10.1029/2011JD015942.

Yu, W., M. Doutriaux, G. Sèze, H. Treut, and M. Desbois, 1996: A methodology study of the validation of clouds in GCMs using ISCCP satellite observations. Climate Dyn., 12, 389-401, doi:10.1007/BF00211685.

Zhang, M. H., and Coauthors, 2005: Comparing clouds and their seasonal variations in 10 atmospheric general circulation models with satellite measurements. J. Geophys. Res., 110, D15S02, doi:10.1029/2004JD005021. 